\title{
Dynamics and Stability Analysis of a Stackelberg Mixed Duopoly Game with Price Competition in Insurance Market
}

\author{
Longfei Wei $\mathbb{D},{ }^{1}$ Haiwei Wang, ${ }^{2}$ Jing Wang $\mathbb{D}^{3}$, and Jialong $\mathrm{Hou}^{4}$ \\ ${ }^{1}$ School of Finance, Dongbei University of Finance and Economics, Dalian 116025, China \\ ${ }^{2}$ The Collaborative Innovation Center, Jiangxi University of Finance and Economics, Nanchang 330013, China \\ ${ }^{3}$ School of Mathematics, Liaoning Normal University, Dalian 116029, China \\ ${ }^{4}$ Department of Electrical and Computer Engineering, University of Florida, Gainesville 32603, Florida, USA \\ Correspondence should be addressed to Jing Wang; wjlnnu@126.com
}

Received 9 April 2021; Revised 17 May 2021; Accepted 2 June 2021; Published 21 June 2021

Academic Editor: Mehmed Nurkanovic

Copyright ( $\odot 2021$ Longfei Wei et al. This is an open access article distributed under the Creative Commons Attribution License, which permits unrestricted use, distribution, and reproduction in any medium, provided the original work is properly cited.

\begin{abstract}
This paper investigates the dynamical behaviors of a Stackelberg mixed duopoly game with price competition in the insurance market, involving one state-owned public insurance company and one private insurance company. We study and compare the stability conditions for the Nash equilibrium points of two sequential-move games, public leadership, and private leadership games. Numerical simulations present complicated dynamic behaviors. It is shown that the Nash equilibrium becomes unstable as the price adjustment speed increases, and the system eventually becomes chaotic via flip bifurcation. Moreover, the time-delayed feedback control is used to force the system back to stability.
\end{abstract}

\section{Introduction}

The insurance market in most countries has shown typical characteristics of an oligopoly market. Most of the existing literature on oligopoly games in the insurance market concentrates on static games, while less on dynamic games. The competition among oligarchs in the insurance market is mainly reflected in price competition. One of the most famous price game models is the Bertrand model. For a long time, the complex dynamics in Bertrand oligopoly games have been researched widely. For instance, Zhang and Ma [1] investigated a nonlinear Bertrand game of insurance market wherein one of the oligarchs made the decision only with bounded rationality without delay, while the other part made the delayed decision with one period and two periods. $\mathrm{Xu}$ and $\mathrm{Ma}$ [2] established a price game model with delay based on the insurance market and discussed the existence and stability of equilibrium points. Ahmed et al. [3] analyzed the dynamic behaviors of a differentiated Bertrand duopoly game, in which boundedly rational players apply a gradient adjustment mechanism to update their price in each period. $\mathrm{Ma}$ and Si [4] introduced a continuous Bertrand duopoly game model with a two-stage delay and investigated the influence of delay parameters on the dynamic characteristics of the system. Zhao [5] studied the dynamic properties of a Bertrand game model with three oligarchs in which enterprises have heterogeneous expectations. Askar and Alkhedhairi [6] introduced two different Bertrand duopoly models where the first one is the competition of price in which each player wants to maximize its relative profit, and the second model is the classic Bertrand competition in which the players want to maximize their profits. There is still some literature which studies the Bertrand game theory and the complexity of the dynamical system; see [7-12]. The above price game models assume that firms play simultaneous-move games; however, the competition among oligarchs in the real market is mostly a dynamic game or sequential game. It is well known that the most classical sequential game is the Stackelberg game. Shi et al. [13] proposed a price-Stackelberg duopoly game model with boundedly rational players and studied the complex dynamical behaviors. Shah et al. [14] applied the Stackelberg game with stochastic demand for the vendor-retailer system. Wang [15] investigated a manufacturer-Stackelberg game in 
a price competition supply chain under a fuzzy decision environment. Xiao et al. [16] analyzed a nonlinear twodimensional duopoly Stackelberg game, including two types of heterogeneous players which are bounded rational players and adaptable players. Other interesting works that can be used to extend the applications of such economic games have been reported in [17-20].

Most countries have state-owned public firms that have a substantial influence on their market competitors. The competition in mixed oligopolies, in which a state-owned public firm competes against a private firm, is widespread in the real market. Such mixed oligopolies occur in various industries, such as automobile, postal services, hospitals, education, banking, and insurance [21]. Analysis of mixed oligopolies can be dated to 1966 when Merrill and Schneider first put forward the assumption that a public firm maximizes welfare (consumer surplus plus firm profits), while private firms maximize profits [22]. Some discussions of the mixed oligopolies were presented in [23-25]. In related works, there are few studies on Stackelberg mixed oligopolies. For instance, Wang and Mukherjee [26] showed welfare under different numbers of private firms under the assumption of a public firm as the Stackelberg leader and private firms as Stackelberg followers. Wang and Lee [27] examined the influence of the order of the firms' moves on the social efficiency with foreign ownership and free entry in a mixed oligopoly market. Tao et al. [28] studied and compared total welfare in Stackelberg mixed duopolies when either the public firm or the private firm acts as the leader. Gelves and Heywood [29] compared the merger between the public leader and the private follower with unilateral privatization of the public leader. Hirose and Matsumura [21] compared welfare and profit under price and quantity competition in Stackelberg mixed duopolies, wherein a state-owned public firm competes against a private firm. These studies mainly focus on quantity competition, less on price competition, and all of them discuss directly the decisions of competitors in Nash equilibrium, and their dynamics have not been studied. However, the dynamic adjustment process converging to Nash equilibrium, and the stability of Nash equilibrium are important in the real market.

In this paper, we pay attention to a Stackelberg mixed duopoly game of price competition between a state-owned public insurance company and a private insurance company in the insurance market and study how this duopoly game evolves to different Nash equilibriums in two sequentialmove games, public leadership and private leadership games. Simulations of the complicated dynamic behaviors and chaos control are presented, and the welfare and profit in Nash equilibrium are also discussed.

The rest of this paper is organized as follows: in Section 2, the Stackelberg mixed duopoly game model with price competition is briefly described. In Section 3, the existence of equilibrium points, the instability of bounded equilibrium, and the local stability conditions of Nash equilibrium in two sequential-move cases are analyzed. In Section 4, numerical simulations are used to show the dynamic features of the game, including bifurcation diagram, maximum Lyapunov exponents, phase portrait, and sensitive dependence on initial conditions. The comparison of welfare and profit in Nash equilibrium under two sequential-move cases is also shown by the figures in this section. In Section 5, timedelayed feedback control is used to suppress the appearance of chaotic behavior for the proposed system. Finally, the paper is concluded in Section 6.

\section{The Model}

We consider the dynamical behaviors of a duopoly price game in the insurance market with two insurance companies (ICs), labeled by $i=1,2$. We assume $\mathrm{IC}_{1}$ is a state-owned public insurance company, while $\mathrm{IC}_{2}$ is a private insurance company, and the two ICs use different decisional mechanisms. Each $\mathrm{IC}_{i}$ chooses a nonnegative real number $p_{i}$, which is the price of its own product. The strategy profile $p=\left(p_{1}, p_{2}\right)$ results in a corresponding market quantity demanded $q=\left(q_{1}, q_{2}\right)$. We adopt a standard duopoly model with differentiated products and linear demand [30, 31]. The utility function of the representative consumer is given by

$$
U\left(q_{1}, q_{2}\right)=\alpha\left(q_{1}+q_{2}\right)-\frac{\beta}{2}\left(q_{1}^{2}+2 \delta q_{1} q_{2}+q_{2}^{2}\right) .
$$

Parameters $\alpha$ and $\beta$ are positive constants and $\delta \in(0,1)$ measures the degree of horizontal differentiation, where a smaller $\delta$ indicates a larger degree of insurance product differentiation. Then, the inverse demand functions are

$$
\left\{\begin{array}{l}
p_{1}=\alpha-\beta q_{1}-\beta \delta q_{2} \\
p_{2}=\alpha-\beta q_{2}-\beta \delta q_{1}
\end{array}\right.
$$

According to equation (2), the direct demand functions can be given by

$$
\left\{\begin{array}{l}
q_{1}=\frac{\alpha-\alpha \delta-p_{1}+\delta p_{2}}{\beta\left(1-\delta^{2}\right)} \\
q_{2}=\frac{\alpha-\alpha \delta-p_{2}+\delta p_{1}}{\beta\left(1-\delta^{2}\right)} .
\end{array}\right.
$$

We denote the marginal cost of $\mathrm{IC}_{i}$ with a positive constant $c_{i}$, assuming $\alpha>c_{1} \geq c_{2}$. In addition, we assume that $\alpha$ is sufficiently large and that $c_{1}-c_{2}$ is not too large to assure interior solutions in the following games. Since $\mathrm{IC}_{1}$ is a public firm, its payoff is the domestic social surplus (welfare) $[21,28]$ and is given by

$$
\pi_{1}=\left(p_{1}-c_{1}\right) q_{1}+\left(p_{2}-c_{2}\right) q_{2}+\left[\alpha\left(q_{1}+q_{2}\right)-\frac{\beta\left(q_{1}^{2}+2 \delta q_{1} q_{2}+q_{2}^{2}\right)}{2}-p_{1} q_{1}-p_{2} q_{2}\right]
$$


For the convenience of expression, equation (4) can be simplified to the following form:

$$
\pi_{1}=\left(\alpha-c_{1}\right) q_{1}+\left(\alpha-c_{2}\right) q_{2}-\frac{\beta\left(q_{1}^{2}+2 \delta q_{1} q_{2}+q_{2}^{2}\right)}{2}
$$

and $\mathrm{IC}_{2}$ is a private firm and its payoff is its own profit:

$$
\pi_{2}=\left(p_{2}-c_{2}\right) q_{2}
$$

In this study, we consider two sequential-move games, public leadership and private leadership games. To construct and investigate the dynamic characteristics of the two games, we assume that both ICs are bounded rational, in which the players modify their price decisions dynamically according to the marginal payoff [32]. When $\mathrm{IC}_{i}\left(\mathrm{IC}_{j}\right)$ is the leader (follower), $i \neq j$, the dynamic system for two ICs has the following form:

$$
\left\{\begin{array}{l}
p_{i}(t+1)=p_{i}(t)+k_{i} p_{i}(t) \frac{\partial \pi_{i}\left(p_{i}(t), p_{j}(t)\right)}{\partial p_{i}(t)}, \\
p_{j}(t+1)=p_{j}(t)+k_{j} p_{j}(t) \frac{\partial \pi_{j}\left(p_{i}(t+1), p_{j}(t)\right)}{\partial p_{j}(t)},
\end{array}\right.
$$

where $k_{i}$ and $k_{j}$ are positive parameters known as the speed of price adjustment and $t=0,1,2, \ldots$. At $t+1$, the leader $\mathrm{IC}_{i}$ takes the lead in determining the price $p_{i}(t+1)$. Then, the follower $\mathrm{IC}_{j}$ chooses $p_{j}(t+1)$ to maximize its own payoff after observing $p_{i}(t+1)$, which can be seen in the second equation of system (7).

\section{Equilibrium Points and Local Stability}

3.1. Public Leadership. In this case, we analyze a Stackelberg model in which $\mathrm{IC}_{1}\left(\mathrm{IC}_{2}\right)$ is the leader (follower). At $t+1$, the leader $\mathrm{IC}_{1}$ takes the lead in determining the price $p_{1}(t+$ 1) on the basis of marginal payoff. The marginal payoff of $\mathrm{IC}_{1}$ is

$$
\frac{\partial \pi_{1}\left(p_{1}(t), p_{2}(t)\right)}{\partial p_{1}(t)}=\frac{\delta\left[\alpha(1-\delta)-c_{2}\right]+2 c_{1}\left(2-\delta^{2}\right)+\left(3 \delta^{2}-4\right) p_{1}(t)}{4 \beta\left(1-\delta^{2}\right)}
$$

Then, we can get

$$
\begin{aligned}
p_{1}(t+1)= & p_{1}(t)+\frac{k_{1} p_{1}(t)}{4 \beta\left(1-\delta^{2}\right)}\left\{\delta\left[\alpha(1-\delta)-c_{2}\right]\right. \\
& \left.+2 c_{1}\left(2-\delta^{2}\right)+\left(3 \delta^{2}-4\right) p_{1}(t)\right\} .
\end{aligned}
$$

The follower $\mathrm{IC}_{2}$ has an advantage over the leader. $\mathrm{IC}_{2}$ has known the current price of $\mathrm{IC}_{1}$ when it chooses its price $p_{2}(t+1)$. Hence, the price of $\mathrm{IC}_{2}$ at period $t+1$ is determined by its own price of period $t$ and $\mathrm{IC}_{1}$ 's price of period $t+1$. Then, the marginal payoff of $\mathrm{IC}_{2}$ is given by

$$
\frac{\partial \pi_{2}\left(p_{1}(t+1), p_{2}(t)\right)}{\partial p_{2}(t)}=\frac{1}{\beta\left(1-\delta^{2}\right)}\left[\alpha(1-\delta)+c_{2}+\delta p_{1}(t)-2 p_{2}(t)\right]+\frac{\delta k_{1} p_{1}(t)}{4 \beta^{2}\left(1-\delta^{2}\right)^{2}}\left\{\delta\left[\alpha(1-\delta)-c_{2}\right]+2 c_{1}\left(2-\delta^{2}\right)+\left(3 \delta^{2}-4\right) p_{1}(t)\right\}
$$

Then, we have

$$
p_{2}(t+1)=p_{2}(t)+\frac{k_{2} p_{2}(t)}{\beta\left(1-\delta^{2}\right)}\left[\alpha(1-\delta)+c_{2}+\delta p_{1}(t)-2 p_{2}(t)\right]+\frac{\delta k_{1} k_{2} p_{1}(t) p_{2}(t)}{4 \beta^{2}\left(1-\delta^{2}\right)^{2}}\left\{\delta\left[\alpha(1-\delta)-c_{2}\right]+2 c_{1}\left(2-\delta^{2}\right)+\left(3 \delta^{2}-4\right) p_{1}(t)\right\}
$$

Thus, the duopoly game can be described by a discretetime dynamic map as follows:

$$
\left\{\begin{array}{l}
p_{1}(t+1)=p_{1}(t)+\frac{k_{1} p_{1}(t)}{4 \beta\left(1-\delta^{2}\right)}\left\{\delta\left[\alpha(1-\delta)-c_{2}\right]+2 c_{1}\left(2-\delta^{2}\right)+\left(3 \delta^{2}-4\right) p_{1}(t)\right\}, \\
p_{2}(t+1)=p_{2}(t)+\frac{k_{2} p_{2}(t)}{\beta\left(1-\delta^{2}\right)}\left[\alpha(1-\delta)+c_{2}+\delta p_{1}(t)-2 p_{2}(t)\right]+\frac{\delta k_{1} k_{2} p_{1}(t) p_{2}(t)}{4 \beta^{2}\left(1-\delta^{2}\right)^{2}}\left\{\delta\left[\alpha(1-\delta)-c_{2}\right]+2 c_{1}\left(2-\delta^{2}\right)+\left(3 \delta^{2}-4\right) p_{1}(t)\right\} .
\end{array}\right.
$$


When the market structure is stable enough at time $t$, $p_{i}(t+1)$ are approximately equal to $p_{i}(t)$. Setting $p_{1}(t+$ $1)=p_{1}(t)$ and $p_{2}(t+1)=p_{2}(t)$ in equation (12), we can get the following equilibria:

$$
\begin{aligned}
& E_{1}=(0,0), \\
& E_{2}=\left(0, \frac{\alpha(1-\delta)+c_{2}}{2}\right), \\
& E_{3}=\left(\frac{\delta\left[\alpha(1-\delta)-c_{2}\right]+2 c_{1}\left(2-\delta^{2}\right)}{4-3 \delta^{2}}, 0\right), \\
& E_{4}=\left(p_{1}^{*}, p_{2}^{*}\right),
\end{aligned}
$$

where

$$
\begin{aligned}
& p_{1}^{*}=\frac{\delta\left[\alpha(1-\delta)-c_{2}\right]+2 c_{1}\left(2-\delta^{2}\right)}{4-3 \delta^{2}}, \\
& p_{2}^{*}=\frac{\left(2-\delta^{2}\right)\left[\alpha(1-\delta)+c_{1} \delta\right]+2 c_{2}\left(1-\delta^{2}\right)}{4-3 \delta^{2}} .
\end{aligned}
$$

The points $E_{1}, E_{2}$, and $E_{3}$ are known as boundary equilibrium points while $E_{4}$ is the Nash equilibrium point. For the stake of economic significance, the equilibrium points should be nonnegative. It is easily concluded that $E_{2}$, $E_{3}$, and $E_{4}$ are all positive according to the conditions that $\alpha, \beta, c_{1}$, and $c_{2}$ are positive parameters, $\delta \in(0,1)$, and $\alpha>c_{1} \geq c_{2}$. $E_{1}$ represents that every IC has no price; $E_{2}$ and $E_{3}$ represent the monopolies $\mathrm{IC}_{1}$ and $\mathrm{IC}_{2}$, respectively; and $E_{4}$ represents both ICs competing in a duopoly game with equilibrium prices of $p_{1}^{*}$ and $p_{2}^{*}$.

To analyze the local stability of the equilibrium points, we consider the Jacobian matrix of system (12), which can be given by

$$
J\left(p_{1}, p_{2}\right)=\left(\begin{array}{cc}
1+k_{1} \mu A+k_{1}\left(3 \delta^{2}-4\right) \mu p_{1} & 0 \\
4 k_{2} \delta \mu p_{2}\left[1+k_{1} \mu A+k_{1}\left(3 \delta^{2}-4\right) \mu p_{1}\right] & 1+4 k_{2} \mu B-8 k_{2} \mu p_{2}+4 k_{1} k_{2} \delta \mu^{2} A p_{1}
\end{array}\right)
$$

where

$$
\begin{aligned}
& A=\delta\left[\alpha(1-\delta)-c_{2}\right]+2 c_{1}\left(2-\delta^{2}\right)+\left(3 \delta^{2}-4\right) p_{1}, \\
& B=\alpha(1-\delta)+c_{2}+\delta p_{1}-2 p_{2}, \\
& \mu=\frac{1}{4 \beta\left(1-\delta^{2}\right)} .
\end{aligned}
$$

Then, the conditions for a stable equilibrium point can be obtained based on the following lemma [33,34].

Lemma 1. Suppose the Jacobian matrix (15) at any fixed point $E\left(\widetilde{p}_{1}, \widetilde{p}_{2}\right)$ has two eigenvalues $\lambda_{1}$ and $\lambda_{2}$, then (i) If $\left|\lambda_{1}\right|<1$ and $\left|\lambda_{2}\right|<1$, then $E\left(\widetilde{p}_{1}, \tilde{p}_{2}\right)$ is locally asymptotically stable and $E\left(\tilde{p}_{1}, \widetilde{p}_{2}\right)$ is called an attracting node

(ii) If $\left|\lambda_{1}\right|>1$ and $\left|\lambda_{2}\right|>1$, then $E\left(\widetilde{p}_{1}, \widetilde{p}_{2}\right)$ is an unstable repelling node

(iii) If $\left|\lambda_{1}\right|<1$ and $\left|\lambda_{2}\right|>1$ (or $\left|\lambda_{1}\right|>1$ and $\left|\lambda_{2}\right|<1$ ), then $E\left(\widetilde{p}_{1}, \tilde{p}_{2}\right)$ is an unstable saddle point

(iv) If $\left|\lambda_{1}\right|=1$ and $\left|\lambda_{2}\right| \neq 1$ (or $\left|\lambda_{1}\right| \neq 1$ and $\left|\lambda_{2}\right|=1$ ), then $E\left(\widetilde{p}_{1}, \tilde{p}_{2}\right)$ is a nonhyperbolic point

Theorem 1. The boundary equilibrium $E_{1}$ is an unstable repelling node.

Proof. At $E_{1}$, the Jacobian matrix takes the form:

$$
J\left(E_{1}\right)=\left(\begin{array}{cc}
1+\frac{k_{1}\left\{\delta\left[\alpha(1-\delta)-c_{2}\right]+2 c_{1}\left(2-\delta^{2}\right)\right\}}{4 \beta\left(1-\delta^{2}\right)} & 0 \\
0 & 1+\frac{k_{2}\left[\alpha(1-\delta)+c_{2}\right]}{\beta\left(1-\delta^{2}\right)}
\end{array}\right) .
$$

The eigenvalues of $J\left(E_{1}\right)$ are given by 


$$
\begin{aligned}
& \lambda_{1}=1+\frac{k_{1}\left\{\delta\left[\alpha(1-\delta)-c_{2}\right]+2 c_{1}\left(2-\delta^{2}\right)\right\}}{4 \beta\left(1-\delta^{2}\right)}, \\
& \lambda_{2}=1+\frac{k_{2}\left[\alpha(1-\delta)+c_{2}\right]}{\beta\left(1-\delta^{2}\right)} .
\end{aligned}
$$

They are both greater than 1 , so the point $E_{1}$ is an unstable repelling node.

Theorem 2. The boundary equilibrium $E_{2}$ is unstable. More precisely, we have the following: (i) If $0<k_{2}<\left(\beta\left(1-\delta^{2}\right) /\left[\alpha(1-\delta)+c_{2}\right]\right)$, then $E_{2}$ is a saddle point

(ii) If $k_{2}=\left(\beta\left(1-\delta^{2}\right) /\left[\alpha(1-\delta)+c_{2}\right]\right)$, then $E_{2}$ is a nonhyperbolic point

(iii) If $k_{2}>\left(\beta\left(1-\delta^{2}\right) /\left[\alpha(1-\delta)+c_{2}\right]\right)$, then $E_{2}$ is a repelling node

Proof. At $E_{2}$, the Jacobian matrix becomes

$$
J\left(E_{2}\right)=\left(\begin{array}{cc}
1+\frac{k_{1}\left\{\delta\left[\alpha(1-\delta)-c_{2}\right]+2 c_{1}\left(2-\delta^{2}\right)\right\}}{4 \beta\left(1-\delta^{2}\right)} & 0 \\
C & 1-\frac{2 k_{2}\left[\alpha(1-\delta)+c_{2}\right]}{\beta\left(1-\delta^{2}\right)}
\end{array}\right)
$$

where

$$
C=\frac{k_{2} \delta\left[\alpha(1-\delta)+c_{2}\right]}{2 \beta\left(1-\delta^{2}\right)}+\frac{k_{1} k_{2} \delta\left[\alpha(1-\delta)+c_{2}\right]\left\{\delta\left[\alpha(1-\delta)-c_{2}\right]+2 c_{1}\left(2-\delta^{2}\right)\right\}}{8 \beta^{2}\left(1-\delta^{2}\right)^{2}}
$$

The eigenvalues of $J\left(E_{2}\right)$ are given by

$$
\begin{aligned}
& \lambda_{1}=1+\frac{k_{1}\left\{\delta\left[\alpha(1-\delta)-c_{2}\right]+2 c_{1}\left(2-\delta^{2}\right)\right\}}{4 \beta\left(1-\delta^{2}\right)}, \\
& \lambda_{2}=1-\frac{2 k_{2}\left[\alpha(1-\delta)+c_{2}\right]}{\beta\left(1-\delta^{2}\right)},
\end{aligned}
$$

$\left|\lambda_{1}\right|>1$ is always satisfied, so $E_{2}$ is unstable. Simple calculations show that $\left|\lambda_{2}\right|<1$ if $0<k_{2}<\left(\beta\left(1-\delta^{2}\right) /[\alpha(1-\right.$ $\left.\left.\delta)+c_{2}\right]\right), \quad\left|\lambda_{2}\right|=1$ if $k_{2}=\left(\beta\left(1-\delta^{2}\right) /\left[\alpha(1-\delta)+c_{2}\right]\right)$, and $\left|\lambda_{2}\right|>1$ if $k_{2}>\left(\beta\left(1-\delta^{2}\right) /\left[\alpha(1-\delta)+c_{2}\right]\right)$. This concludes the proof.
Theorem 3. The boundary equilibrium $E_{3}$ is unstable. More precisely, we have the following:

(i) If $0<k_{1}<\left(8 \beta\left(1-\delta^{2}\right) /\left\{\delta\left[\alpha \quad(1-\delta)-c_{2}\right]+2 c_{1}(2-\right.\right.$ $\left.\left.\left.\delta^{2}\right)\right\}\right)$, then $E_{3}$ is a saddle point

(ii) If $k_{1}=\left(8 \beta\left(1-\delta^{2}\right) /\left\{\delta\left[\alpha(1-\delta)-c_{2}\right]+2 c_{1}(2-\right.\right.$ $\left.\left.\left.\delta^{2}\right)\right\}\right)$, then $E_{3}$ is a nonhyperbolic point

(iii) If $k_{1}>\left(8 \beta\left(1-\delta^{2}\right) /\left\{\delta\left[\alpha(1-\delta)-c_{2}\right]+2 c_{1}\left(2-\delta^{2}\right)\right\}\right)$, then $E_{3}$ is a repelling node

Proof. At $E_{3}$, the Jacobian matrix is

$$
J\left(E_{3}\right)=\left(\begin{array}{cc}
1-\frac{k_{1}\left\{\delta\left[\alpha(1-\delta)-c_{2}\right]+2 c_{1}\left(2-\delta^{2}\right)\right\}}{4 \beta\left(1-\delta^{2}\right)} & 0 \\
0 & 1+\frac{2 k_{2}\left\{\left(2-\delta^{2}\right)\left[\alpha(1-\delta)+c_{1}\right]+2 c_{1}\left(1-\delta^{2}\right)\right\}}{\beta\left(1-\delta^{2}\right)\left(4-3 \delta^{2}\right)}
\end{array}\right)
$$

The eigenvalues of $J\left(E_{3}\right)$ are given by 


$$
\begin{aligned}
& \lambda_{1}=1-\frac{k_{1}\left\{\delta\left[\alpha(1-\delta)-c_{2}\right]+2 c_{1}\left(2-\delta^{2}\right)\right\}}{4 \beta\left(1-\delta^{2}\right)}, \\
& \lambda_{2}=1+\frac{2 k_{2}\left\{\left(2-\delta^{2}\right)\left[\alpha(1-\delta)+c_{1}\right]+2 c_{1}\left(1-\delta^{2}\right)\right\}}{\beta\left(1-\delta^{2}\right)\left(4-3 \delta^{2}\right)},
\end{aligned}
$$

$\left|\lambda_{2}\right|>1$ is always satisfied, so $E_{3}$ is unstable. Simple calculations show that $\left|\lambda_{1}\right|<1$ if $0<k_{1}<\left(8 \beta\left(1-\delta^{2}\right) /\{\delta[\alpha\right.$ $\left.\left.\left.(1-\delta)-c_{2}\right]+2 c_{1}\left(2-\delta^{2}\right)\right\}\right), \quad\left|\lambda_{1}\right|=1$ if $k_{1}=\left(8 \beta\left(1-\delta^{2}\right) /\right.$ $\left.\left\{\delta\left[\alpha(1-\delta)-c_{2}\right]+2 c_{1}\left(2-\delta^{2}\right)\right\}\right)$, and $\left|\lambda_{1}\right|>1$ if $k_{1}>(8 \beta(1-$ $\left.\left.\delta^{2}\right) /\left\{\delta\left[\alpha(1-\delta)-c_{2}\right]+2 c_{1}\left(2-\delta^{2}\right)\right\}\right)$. This concludes the proof.

The boundary equilibrium points correspond to the situation of one or both ICs going bankrupt. That is, the duopoly market becomes a monopoly, or both of the ICs are out of the insurance market at the same time. However, from an economic point of view, we should pay more attention to the situation of the duopoly market. Hence, we are more interested in investigating the local stability properties of the Nash equilibrium point $E_{4}$. The Jacobian matrix at $E_{4}$ takes the form:

$$
J\left(E_{4}\right)=\left(\begin{array}{cc}
1-\frac{k_{1}\left(4-3 \delta^{2}\right) p_{1}^{*}}{4 \beta\left(1-\delta^{2}\right)} & 0 \\
\frac{k_{2} \delta p_{2}^{*}}{\beta\left(1-\delta^{2}\right)}-\frac{k_{1} k_{2} \delta\left(4-3 \delta^{2}\right) p_{1}^{*} p_{2}^{*}}{4 \beta^{2}\left(1-\delta^{2}\right)^{2}} & 1-\frac{2 k_{2} p_{2}^{*}}{\beta\left(1-\delta^{2}\right)}
\end{array}\right) .
$$

The characteristic equation is

$$
\lambda^{2}-\operatorname{Tr}\left(J\left(E_{4}\right)\right) \lambda+\operatorname{Det}\left(J\left(E_{4}\right)\right)=0,
$$

where $\mathrm{Tr}$ is the trace and Det is the determinant, which are given by

$$
\begin{aligned}
\operatorname{Tr}\left(J\left(E_{4}\right)\right) & =2-\frac{k_{1}\left(4-3 \delta^{2}\right) p_{1}^{*}}{4 \beta\left(1-\delta^{2}\right)}-\frac{2 k_{2} p_{2}^{*}}{\beta\left(1-\delta^{2}\right)}, \\
\operatorname{Det}\left(J\left(E_{4}\right)\right) & =1-\frac{k_{1}\left(4-3 \delta^{2}\right) p_{1}^{*}}{4 \beta\left(1-\delta^{2}\right)}-\frac{2 k_{2} p_{2}^{*}}{\beta\left(1-\delta^{2}\right)}+\frac{k_{1} k_{2}\left(4-3 \delta^{2}\right) p_{1}^{*} p_{2}^{*}}{2 \beta^{2}\left(1-\delta^{2}\right)^{2}} .
\end{aligned}
$$

Then, we have

$$
\operatorname{Tr}\left(J\left(E_{4}\right)\right)^{2}-4 \operatorname{Det}\left(J\left(E_{4}\right)\right)=\left(\frac{k_{1}\left(4-3 \delta^{2}\right) p_{1}^{*}}{4 \beta\left(1-\delta^{2}\right)}-\frac{2 k_{2} p_{2}^{*}}{\beta\left(1-\delta^{2}\right)}\right)^{2}
$$

which indicates that the eigenvalues are real. According to Jury conditions [35], the necessary and sufficient conditions for the local stability of $E_{4}$ are as follows:

$$
\left\{\begin{array}{l}
1-\operatorname{Det}\left(J\left(E_{4}\right)\right)>0, \\
1-\operatorname{Tr}\left(J\left(E_{4}\right)\right)+\operatorname{Det}\left(J\left(E_{4}\right)\right)>0, \\
1+\operatorname{Tr}\left(J\left(E_{4}\right)\right)+\operatorname{Det}\left(J\left(E_{4}\right)\right)>0 .
\end{array}\right.
$$

The above conditions are, respectively, equivalent to

(i) $\frac{k_{1}\left(4-3 \delta^{2}\right) p_{1}^{*}}{4 \beta\left(1-\delta^{2}\right)}+\frac{2 k_{2} p_{2}^{*}}{\beta\left(1-\delta^{2}\right)}-\frac{k_{1} k_{2}\left(4-3 \delta^{2}\right) p_{1}^{*} p_{2}^{*}}{2 \beta^{2}\left(1-\delta^{2}\right)^{2}}>0$,

(ii) $\frac{k_{1} k_{2}\left(4-3 \delta^{2}\right) p_{1}^{*} p_{2}^{*}}{2 \beta^{2}\left(1-\delta^{2}\right)^{2}}>0$,

(iii) $4-\frac{k_{1}\left(4-3 \delta^{2}\right) p_{1}^{*}}{2 \beta\left(1-\delta^{2}\right)}-\frac{4 k_{2} p_{2}^{*}}{\beta\left(1-\delta^{2}\right)}+\frac{k_{1} k_{2}\left(4-3 \delta^{2}\right) p_{1}^{*} p_{2}^{*}}{2 \beta^{2}\left(1-\delta^{2}\right)^{2}}>0$

Clearly, the condition (ii) is always satisfied. Then, the following result can be obtained from the derivation of conditions (i) and (iii).

Theorem 4. The Nash equilibrium point $E_{4}$ is asymptotically locally stable if

$$
\begin{aligned}
& k_{1}<\frac{8 \beta\left(1-\delta^{2}\right)}{\left(4-3 \delta^{2}\right) p_{1}^{*}}, \\
& k_{2}<\frac{\beta\left(1-\delta^{2}\right)}{p_{2}^{*}} .
\end{aligned}
$$

Proof. Inequality (29) can be rewritten as

$$
\frac{8 \beta\left(1-\delta^{2}\right)}{k_{1}\left(4-3 \delta^{2}\right) p_{1}^{*}}+\frac{\beta\left(1-\delta^{2}\right)}{k_{2} p_{2}^{*}}>2 .
$$

Inequality (31) can be modified as

$$
4-\frac{k_{1}\left(4-3 \delta^{2}\right) p_{1}^{*}}{2 \beta\left(1-\delta^{2}\right)}-\frac{4 k_{2} p_{2}^{*}}{\beta\left(1-\delta^{2}\right)}+\frac{k_{1} k_{2}\left(4-3 \delta^{2}\right) p_{1}^{*} p_{2}^{*}}{2 \beta^{2}\left(1-\delta^{2}\right)^{2}}=4\left(1-\frac{k_{1}\left(4-3 \delta^{2}\right) p_{1}^{*}}{8 \beta\left(1-\delta^{2}\right)}\right)\left(1-\frac{k_{2} p_{2}^{*}}{\beta\left(1-\delta^{2}\right)}\right)>0 .
$$

Inequality (34) holds if and only if the following two conditions are satisfied: 


$$
\begin{aligned}
& k_{1}<\frac{8 \beta\left(1-\delta^{2}\right)}{\left(4-3 \delta^{2}\right) p_{1}^{*},} \\
& k_{2}<\frac{\beta\left(1-\delta^{2}\right)}{p_{2}^{*}},
\end{aligned}
$$

or

$$
\begin{aligned}
& k_{1}>\frac{8 \beta\left(1-\delta^{2}\right)}{\left(4-3 \delta^{2}\right) p_{1}^{*}}, \\
& k_{2}>\frac{\beta\left(1-\delta^{2}\right)}{p_{2}^{*}} .
\end{aligned}
$$

It is obvious that the first condition implies inequality (33). On the other hand, inequality (33) is impossible in the $\left(k_{1}, k_{2}\right)$-plane determined by the second condition. This concludes the proof.

Condition (32) defines a stability region in the plane of the price adjustment speed $\left(k_{1}, k_{2}\right)$ (see Figure 1(a)). The boundary intersects the axes $k_{1}$ and $k_{2}$ at points $R_{1}$ and $R_{2}$, respectively, whose coordinates are

$$
\begin{aligned}
& R_{1}=\left(\frac{8 \beta\left(1-\delta^{2}\right)}{\left(4-3 \delta^{2}\right) p_{1}^{*}}, 0\right), \\
& R_{2}=\left(0, \frac{\beta\left(1-\delta^{2}\right)}{p_{2}^{*}}\right) .
\end{aligned}
$$

Simple calculations show that if $k_{1}=\left(8 \beta\left(1-\delta^{2}\right) /(4-\right.$ $\left.\left.3 \delta^{2}\right) p_{1}^{*}\right)$ or $k_{2}=\left(\beta\left(1-\delta^{2}\right) / p_{2}^{*}\right)$, one of the absolute values of eigenvalues is equal to 1 . Inequalities (29) and (31) define a bounded region of stability beyond which a flip bifurcation and a Neimark-Sacker bifurcation occur, respectively $[33,36]$. According to Theorem 4, we can get that the Nash equilibrium point $E_{4}$ loses its stability only via flip bifurcation when one or both values of $k_{1}$ and $k_{2}$ are greater than the boundary values of the stability region.

According to the expressions of the coordinate value of the boundary points, we can clearly find out the effects of the changing values of parameters $\alpha, \beta, c_{1}$, and $c_{2}$ on the stability region, respectively, but it is difficult to directly observe how parameter $\delta$ affects the stability regions from the expression. By computer work on the stability conditions for four cases $(\delta=0.05,0.3,0.5,0.7)$, the stability regions in the $\left(k_{1}, k_{2}\right)$-plane are numerically obtained and are plotted in Figure 1(a). We can see that increasing $\delta$ reduces the stability region, and the stability of system (12) is more sensitive to $\mathrm{IC}_{2}$. If $k_{2}$ is relatively lower, even if $k_{1}$ is relatively higher, system (12) is stable.

3.2. Private Leadership. When $\mathrm{IC}_{2}\left(\mathrm{IC}_{1}\right)$ is the leader (follower), we can write system (7) as

$$
\left\{\begin{aligned}
p_{1}(t+1)= & p_{1}(t)+\frac{k_{1} p_{1}(t)}{\beta\left(1-\delta^{2}\right)}\left(c_{1}-\delta c_{2}-p_{1}(t)+\delta p_{2}(t)\right) \\
& +\frac{\delta k_{1} k_{2} p_{1}(t) p_{2}(t)}{\beta^{2}\left(1-\delta^{2}\right)^{2}}\left[\alpha(1-\delta)+\delta c_{1}+\left(1-2 \delta^{2}\right) c_{2}-2\left(1-\delta^{2}\right) p_{2}(t)\right] \\
p_{2}(t+1)= & p_{2}(t)+\frac{k_{2} p_{2}(t)}{\beta\left(1-\delta^{2}\right)}\left[\alpha(1-\delta)+\delta c_{1}+\left(1-2 \delta^{2}\right) c_{2}-2\left(1-\delta^{2}\right) p_{2}(t)\right] .
\end{aligned}\right.
$$

Setting $p_{1}(t+1)=p_{1}(t)$ and $p_{2}(t+1)=p_{2}(t)$ in equation (38), we have the following equilibria:

$$
\begin{aligned}
& E_{5}=(0,0), \\
& E_{6}=\left(0, \frac{\alpha(1-\delta)+\delta c_{1}+\left(1-2 \delta^{2}\right) c_{2}}{2\left(1-\delta^{2}\right)}\right), \\
& E_{7}=\left(c_{1}-\delta c_{2}, 0\right), \\
& E_{8}=\left(p_{1}^{* *}, p_{2}^{* *}\right),
\end{aligned}
$$

where

$$
\begin{aligned}
& p_{1}^{* *}=\frac{\delta\left[\alpha(1-\delta)-c_{2}\right]+\left(2-\delta^{2}\right) c_{1}}{2\left(1-\delta^{2}\right)}, \\
& p_{2}^{* *}=\frac{\alpha(1-\delta)+\delta c_{1}+\left(1-2 \delta^{2}\right) c_{2}}{2\left(1-\delta^{2}\right)} .
\end{aligned}
$$

Points $E_{5}, E_{6}$, and $E_{7}$ are boundary equilibrium points and $E_{8}$ is the unique Nash equilibrium point. It is clear that $E_{6}, E_{7}$, and $E_{8}$ are all positive according to the conditions that $\alpha, \beta, c_{1}$, and $c_{2}$ are positive parameters, $\delta \in(0,1)$, and $\alpha>c_{1} \geq c_{2}$.

The Jacobian matrix of system (38) can be given by 

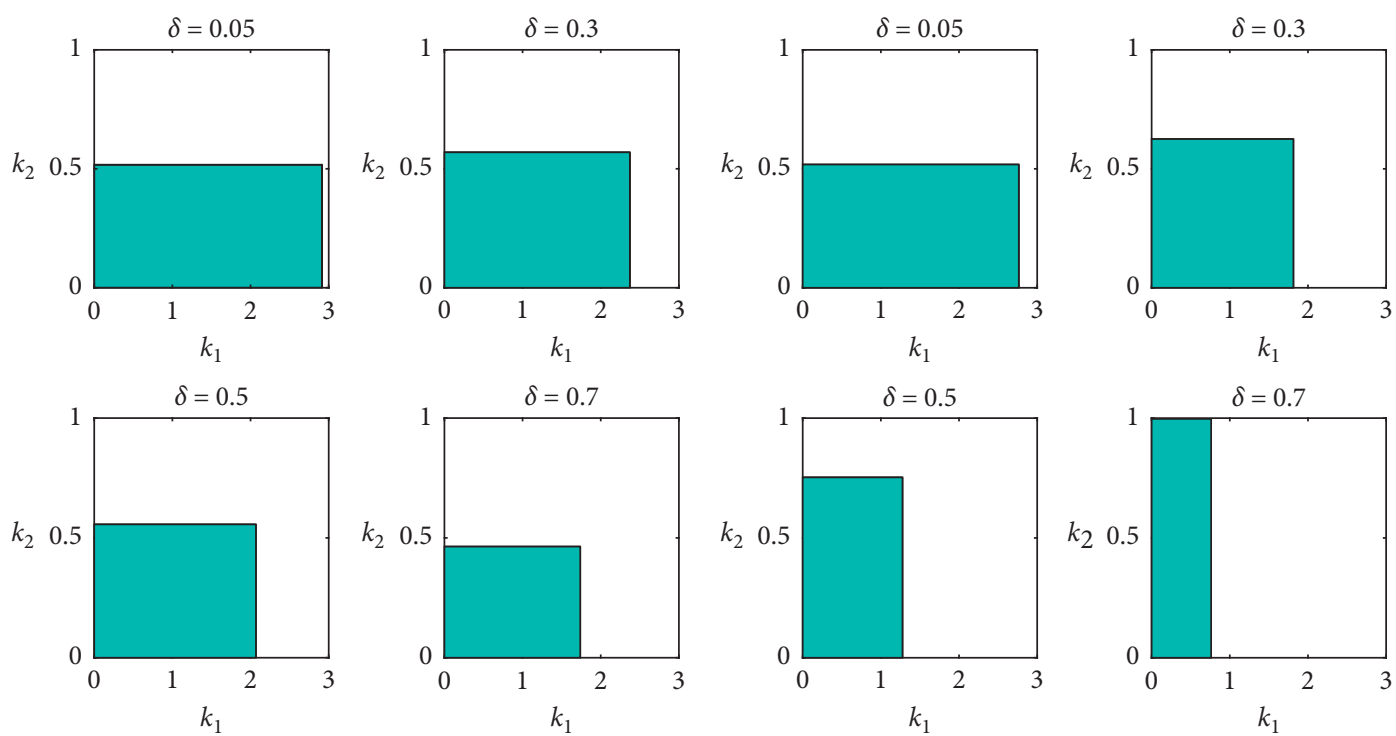

(a)

(b)

Figure 1: (a) The stability regions in the $\left(k_{1}, k_{2}\right)$-plane of Nash equilibrium point $E_{4}$ for system (12) with different levels of $\delta$. (b) The stability regions in the $\left(k_{1}, k_{2}\right)$-plane of Nash equilibrium point $E_{8}$ for system (38) with different levels of $\delta$. The other values of the parameters are $\alpha=0.7, \beta=0.2, c_{1}=0.13$, and $c_{2}=0.1$.

$$
J\left(p_{1}, p_{2}\right)=\left(\begin{array}{cc}
1+k_{1} \mu^{\prime} B^{\prime}-k_{1} \mu^{\prime} p_{1}+k_{1} k_{2} \delta \mu^{\prime 2} A^{\prime} p_{2} & k_{1} \delta \mu^{\prime} p_{1}\left[1+k_{2} \mu^{\prime} A^{\prime}-2 k_{2}\left(1-\delta^{2}\right) \mu^{\prime} p_{2}\right] \\
0 & 1+k_{2} \mu^{\prime} A^{\prime}-2 k_{2}\left(1-\delta^{2}\right) \mu^{\prime} p_{2}
\end{array}\right),
$$

where

$$
\begin{aligned}
& A^{\prime}=\alpha(1-\delta)+\delta c_{1}+\left(1-2 \delta^{2}\right) c_{2}-2\left(1-\delta^{2}\right) p_{2} \\
& B^{\prime}=c_{1}-\delta c_{2}-p_{1}+\delta p_{2}, \\
& \mu^{\prime}=\frac{1}{\beta\left(1-\delta^{2}\right)}
\end{aligned}
$$

Theorem 5. The boundary equilibrium $E_{5}$ is an unstable repelling node.

Proof. The Jacobian matrix (41) at the point $E_{5}$ takes the form:

$$
J\left(E_{5}\right)=\left(\begin{array}{cc}
1+\frac{k_{1}\left(c_{1}-\delta c_{2}\right)}{\beta\left(1-\delta^{2}\right)} & 0 \\
0 & 1+\frac{k_{2}\left[\alpha(1-\delta)+\delta c_{1}+\left(1-2 \delta^{2}\right) c_{2}\right]}{\beta\left(1-\delta^{2}\right)}
\end{array}\right)
$$

The eigenvalues of $J\left(E_{5}\right)$ are given by

$$
\begin{aligned}
& \lambda_{1}=1+\frac{k_{1}\left(c_{1}-\delta c_{2}\right)}{\beta\left(1-\delta^{2}\right)}, \\
& \lambda_{2}=1+\frac{k_{2}\left[\alpha(1-\delta)+\delta c_{1}+\left(1-2 \delta^{2}\right) c_{2}\right]}{\beta\left(1-\delta^{2}\right)} .
\end{aligned}
$$

It is clear that they are both greater than 1 , so the point $E_{5}$ is an unstable repelling node.

Theorem 6. The boundary equilibrium $E_{6}$ is unstable. More precisely, we have the following:

(i) If $0<k_{2}<\left(2 \beta\left(1-\delta^{2}\right) /\left[\alpha(1-\delta)+\delta c_{1}+\left(1-2 \delta^{2}\right)\right.\right.$ $\left.\left.c_{2}\right]\right)$, then $E_{6}$ is a saddle point 
(ii) If $k_{2}=\left(2 \beta\left(1-\delta^{2}\right) /\left[\alpha(1-\delta)+\delta c_{1}+\left(1-2 \delta^{2}\right) c_{2}\right]\right)$, then $E_{6}$ is a nonhyperbolic point

(iii) If $k_{2}>\left(2 \beta\left(1-\delta^{2}\right) /\left[\alpha(1-\delta)+\delta c_{1}+\left(1-2 \delta^{2}\right) c_{2}\right]\right)$, then $E_{6}$ is a repelling node
Proof. At $E_{6}$, the Jacobian matrix becomes

$$
J\left(E_{6}\right)=\left(\begin{array}{c}
1+\frac{k_{1}\left[2 c_{1}-\delta c_{2}+\alpha \delta(1-\delta)\right]}{2 \beta\left(1-\delta^{2}\right)^{2}} \\
0
\end{array}\right.
$$

$\left|\lambda_{1}\right|>1$ is always satisfied, so $E_{6}$ is unstable. Simple calculations show that $\left|\lambda_{2}\right|<1$ if $0<k_{2}<\left(2 \beta\left(1-\delta^{2}\right) /\right.$ $\left.\left[\alpha(1-\delta)+\delta c_{1}+\left(1-2 \delta^{2}\right) c_{2}\right]\right), \quad\left|\lambda_{2}\right|=1 \quad$ if $\quad k_{2}=(2 \beta(1-$ $\left.\left.\delta^{2}\right) /\left[\alpha(1-\delta)+\delta c_{1}+\left(1-2 \delta^{2}\right) c_{2}\right]\right)$, and $\left|\lambda_{2}\right|>1$ if $k_{2}>$ $\left(2 \beta\left(1-\delta^{2}\right) /\left[\alpha(1-\delta)+\delta c_{1}+\left(1-2 \delta^{2}\right) c_{2}\right]\right)$. This concludes the proof.

$$
\left.1-\frac{k_{2}\left[\alpha(1-\delta)+\delta c_{1}+\left(1-2 \delta^{2}\right) c_{2}\right]}{\beta\left(1-\delta^{2}\right)}\right) \text {. }
$$

$$
\begin{aligned}
& \lambda_{1}=1+\frac{k_{1}\left[2 c_{1}-\delta c_{2}+\alpha \delta(1-\delta)\right]}{2 \beta\left(1-\delta^{2}\right)^{2}}, \\
& \lambda_{2}=1-\frac{k_{2}\left[\alpha(1-\delta)+\delta c_{1}+\left(1-2 \delta^{2}\right) c_{2}\right]}{\beta\left(1-\delta^{2}\right)},
\end{aligned}
$$

The eigenvalues of $J\left(E_{6}\right)$ are given by

Proof. At $E_{7}$, the Jacobian matrix is
Theorem 7. The boundary equilibrium $E_{7}$ is unstable. More precisely, we have the following:

(i) If $0<k_{1}<\left(2 \beta\left(1-\delta^{2}\right) /\left(c_{1}-\delta c_{2}\right)\right)$, then $E_{7}$ is a saddle point

(ii) If $k_{1}=\left(2 \beta\left(1-\delta^{2}\right) /\left(c_{1}-\delta c_{2}\right)\right)$, then $E_{7}$ is a nonhyperbolic point

(iii) If $k_{1}>\left(2 \beta\left(1-\delta^{2}\right) /\left(c_{1}-\delta c_{2}\right)\right)$, then $E_{7}$ is a repelling node

$$
J\left(E_{7}\right)=\left(\begin{array}{cc}
1-\frac{k_{1}\left(c_{1}-\delta c_{2}\right)}{\beta\left(1-\delta^{2}\right)} \frac{k_{1} \delta\left(c_{1}-\delta c_{2}\right)}{\beta\left(1-\delta^{2}\right)}+\frac{k_{1} k_{2} \delta\left(c_{1}-\delta c_{2}\right)\left[\alpha(1-\delta)+\delta c_{1}+\left(1-2 \delta^{2}\right) c_{2}\right]}{\beta^{2}\left(1-\delta^{2}\right)^{2}} \\
0 & 1+\frac{k_{2}\left[\alpha(1-\delta)+\delta c_{1}+\left(1-2 \delta^{2}\right) c_{2}\right]}{\beta\left(1-\delta^{2}\right)}
\end{array}\right) .
$$

The eigenvalues of $J\left(E_{7}\right)$ are given by

$$
\begin{aligned}
& \lambda_{1}=1-\frac{k_{1}\left(c_{1}-\delta c_{2}\right)}{\beta\left(1-\delta^{2}\right)}, \\
& \lambda_{2}=1+\frac{k_{2}\left[\alpha(1-\delta)+\delta c_{1}+\left(1-2 \delta^{2}\right) c_{2}\right]}{\beta\left(1-\delta^{2}\right)},
\end{aligned}
$$

$\left|\lambda_{2}\right|>1$ is always satisfied, so $E_{7}$ is unstable. Simple calculations show that $\left|\lambda_{1}\right|<1$ if $0<k_{1}<\left(2 \beta\left(1-\delta^{2}\right) /\left(c_{1}-\delta c_{2}\right)\right)$, $\left|\lambda_{1}\right|=1$ if $k_{1}=\left(2 \beta\left(1-\delta^{2}\right) /\left(c_{1}-\delta c_{2}\right)\right)$, and $\left|\lambda_{1}\right|>1$ if $k_{1}>\left(2 \beta\left(1-\delta^{2}\right) /\left(c_{1}-\delta c_{2}\right)\right)$. This concludes the proof.

Next, we investigate the local stability properties of the Nash equilibrium point $E_{8}$. The Jacobian matrix at the point $E_{8}$ takes the form:

$$
J\left(E_{8}\right)=\left(\begin{array}{cc}
1-\frac{k_{1} p_{1}^{* *}}{\beta\left(1-\delta^{2}\right)} & \frac{k_{1} \delta p_{1}^{* *}}{\beta\left(1-\delta^{2}\right)}-\frac{2 k_{1} k_{2} \delta p_{1}^{* *} p_{2}^{* *}}{\beta^{2}\left(1-\delta^{2}\right)} \\
0 & 1-\frac{2 k_{2} p_{2}^{* *}}{\beta}
\end{array}\right) \text {. }
$$

The trace and determinant of $J\left(E_{8}\right)$ are

$$
\begin{aligned}
\operatorname{Tr}\left(J\left(E_{8}\right)\right) & =2-\frac{k_{1} p_{1}^{* *}}{\beta\left(1-\delta^{2}\right)}-\frac{2 k_{2} p_{2}^{* *}}{\beta}, \\
\operatorname{Det}\left(J\left(E_{8}\right)\right) & =1-\frac{k_{1} p_{1}^{* *}}{\beta\left(1-\delta^{2}\right)}-\frac{2 k_{2} p_{2}^{* *}}{\beta}+\frac{2 k_{1} k_{2} p_{1}^{* *} p_{2}^{* *}}{\beta^{2}\left(1-\delta^{2}\right)} .
\end{aligned}
$$


Then, we have

$\operatorname{Tr}\left(J\left(E_{8}\right)\right)^{2}-4 \operatorname{Det}\left(J\left(E_{8}\right)\right)=\left(\frac{k_{1} p_{1}^{* *}}{\beta\left(1-\delta^{2}\right)}-\frac{2 k_{2} p_{2}^{* *}}{\beta}\right)^{2}$

It indicates that the eigenvalues are real. According to Jury conditions, the necessary and sufficient conditions for the local stability of $E_{8}$ can be given by

$$
\begin{aligned}
& \text { (i) } \frac{k_{1} p_{1}^{* *}}{\beta\left(1-\delta^{2}\right)}+\frac{2 k_{2} p_{2}^{* *}}{\beta}-\frac{2 k_{1} k_{2} p_{1}^{* *} p_{2}^{* *}}{\beta^{2}\left(1-\delta^{2}\right)}>0, \\
& \text { (ii) } \frac{2 k_{1} k_{2} p_{1}^{* *} p_{2}^{* *}}{\beta^{2}\left(1-\delta^{2}\right)}>0 \\
& \text { (iii) } 4-\frac{2 k_{1} p_{1}^{* *}}{\beta\left(1-\delta^{2}\right)}-\frac{4 k_{2} p_{2}^{* *}}{\beta}+\frac{2 k_{1} k_{2} p_{1}^{* *} p_{2}^{* *}}{\beta^{2}\left(1-\delta^{2}\right)}>0
\end{aligned}
$$

Clearly, condition (ii) is always satisfied. According to conditions (i) and (iii), we have the following result.

Theorem 8. The Nash equilibrium point $E_{8}$ is asymptotically locally stable if

$$
\begin{aligned}
& k_{1}<\frac{2 \beta\left(1-\delta^{2}\right)}{p_{1}^{* *}}, \\
& k_{2}<\frac{\beta}{p_{2}^{* *}} .
\end{aligned}
$$

Proof. Inequality (52) can be rewritten as

$$
\frac{2 \beta\left(1-\delta^{2}\right)}{k_{1} p_{1}^{* *}}+\frac{\beta}{k_{2} p_{2}^{* *}}>2 .
$$

Inequality (54) can be modified as

$$
\begin{aligned}
& 4-\frac{2 k_{1} p_{1}^{* *}}{\beta\left(1-\delta^{2}\right)}-\frac{4 k_{2} p_{2}^{* *}}{\beta}+\frac{2 k_{1} k_{2} p_{1}^{* *} p_{2}^{* *}}{\beta^{2}\left(1-\delta^{2}\right)} \\
& =4\left(1-\frac{k_{1} p_{1}^{* *}}{2 \beta\left(1-\delta^{2}\right)}\right)\left(1-\frac{k_{2} p_{2}^{* *}}{\beta}\right)>0 .
\end{aligned}
$$

We complete the proof by imitating the discussions in Theorem 4.

The stability region for the Nash equilibrium point $E_{8}$ is defined by the inequalities in condition (55). The boundary curve intersects the axes $k_{1}$ and $k_{2}$ at points $R_{3}$ and $R_{4}$, respectively, whose coordinates are

$$
\begin{aligned}
& R_{3}=\left(\frac{2 \beta\left(1-\delta^{2}\right)}{p_{1}^{* *}}, 0\right), \\
& R_{4}=\left(0, \frac{\beta}{p_{2}^{* *}}\right) .
\end{aligned}
$$

Simple calculations show that if $k_{1}=\left(2 \beta\left(1-\delta^{2}\right) / p_{1}^{* *}\right)$ or $k_{2}=\left(\beta / p_{2}^{* *}\right)$, one of the absolute values of eigenvalues is equal to 1 . According to Theorem 8 , we can get that the Nash equilibrium point $E_{8}$ is stable inside the stability region, and loses its stability through flip bifurcation. By computer work on the stability conditions for four cases $(\delta=0.05,0.3,0.5,0.7)$, the stability regions of Nash equilibrium point $E_{8}$ in the $\left(k_{1}, k_{2}\right)$-plane are shown in Figure 1(b). Comparing Figures 1(a) and 1(b), we see that when the parameter $\delta$ is close to zero, the stability regions of Nash equilibrium points $E_{4}$ and $E_{8}$ are similar, but the difference between them becomes larger with the increase of the parameter $\delta$.

\section{Numerical Simulation}

In this section, we perform some numerical simulations for the complex dynamical behaviors of systems (12) and (38) and show how the systems evolve under different levels of parameters. Such simulations include a bifurcation diagram, maximum Lyapunov exponents, phase portrait, and sensitive dependence on initial conditions to further study the unpredictable behavior of the game. In all numerical simulations, parameters $\alpha, \beta, \delta, c_{1}$, and $c_{2}$ are commonly set as $\alpha=0.7, \beta=0.2, \delta=0.5, c_{1}=0.13$, and $c_{2}=0.1$. We perform numerical simulations for the following two situations, respectively.

4.1. Public Leadership. In a real insurance market, the demand function and their marginal costs are relatively certain, so the price adjustment speed is regarded as an important strategy for ICs to pursue profit maximization. In this case, we show by numerical simulations how system (12) evolves under different levels of the parameter $k_{1}$, the price adjustment speed of $\mathrm{IC}_{1}$. We fix the parameter $k_{2}=0.5$, and the bifurcation diagram with respect to the fact that parameter $k_{1}$ is plotted in Figure 2(a). It shows that the equilibrium point begins stable; increasing the value of $k_{1}$ gives the appearance of a stable 2-cycle period through flip bifurcation, then increasing the value of $k_{1}$ further shows a sequence of period-doubling bifurcations followed by cycles with high periodicity; and chaotic scenario occurs in the end. The corresponding maximum Lyapunov exponents are plotted in Figure 2(b) to show bifurcation and chaos, where positive values show the chaotic behaviors.

The observations from Figure 2(a) tell that system (12) becomes unstable through the period-doubling bifurcation when the parameter takes suitable values. About the case in Figure 2, five two-dimension phase portraits for different values of $k_{1}$ are shown in Figure 3, which give a more detailed description of the orbits of system (12). The phase portraits show a flip bifurcation process, where chaos occurs when $k_{1}$ takes its value big enough, and strange attractors can be seen in the fifth phase portrait in Figure 3. The strange attractor reflects the complexity of ICs' dynamic price competition in chaos.

The sensitivity to initial conditions is also one of the important characteristics of chaos. Figure 4 reflects the case 


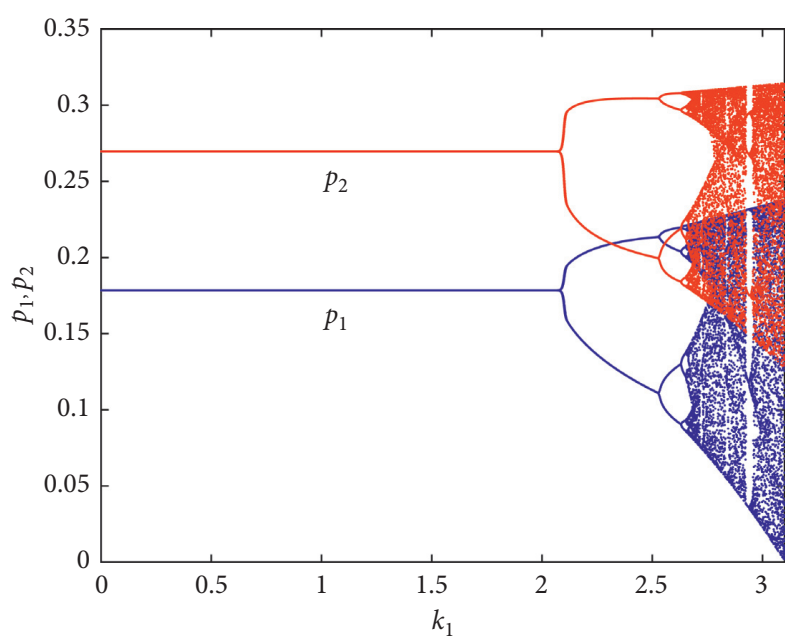

(a)

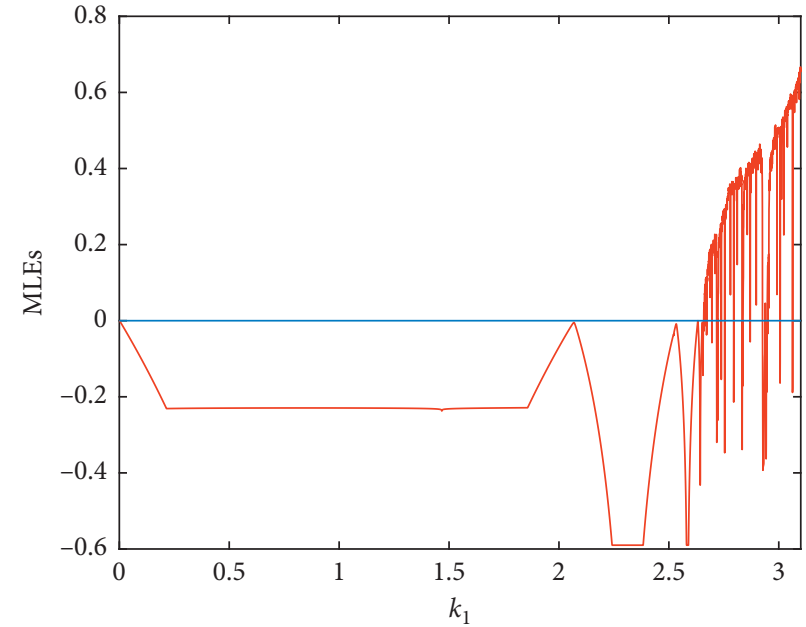

(b)

Figure 2: Bifurcation diagram and MLEs for system (12) with respect to parameter $k_{1}$ when $k_{2}=0.5$.
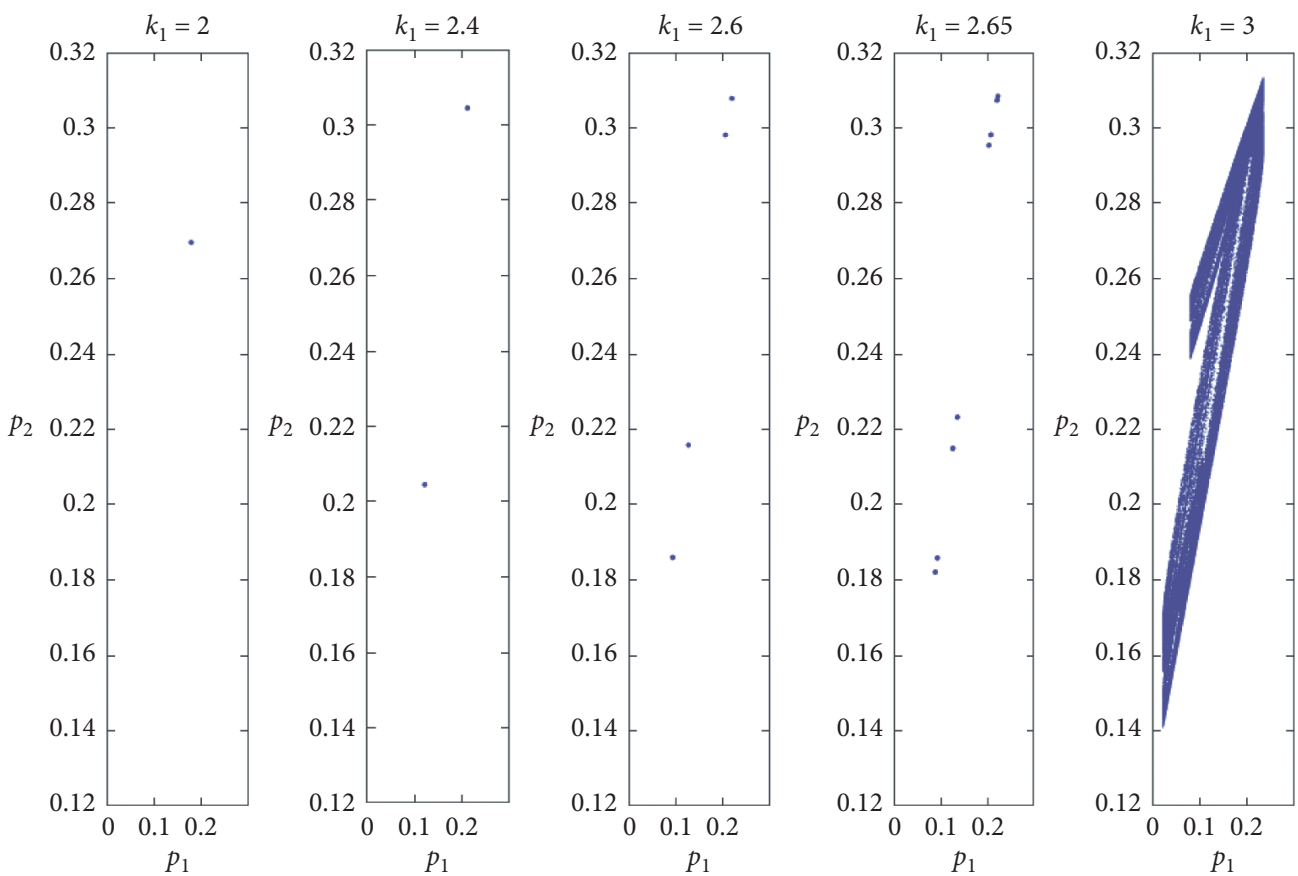

FIGURE 3: Phase portraits for Figure 2 with various values of $k_{1}$.

that the initial state $p_{1}$ ranges from 0.1785 to 0.1786 with other parameters keeping fixed. Figures 4(a) and 4(b) show the orbits of $\mathrm{IC}_{1}$ 's price and $\mathrm{IC}_{2}$ 's price, respectively, where the blue ones (labeled by superscript (1)) start from the initial point $\left(p_{1}^{1}(0), p_{2}^{1}(0)\right)=(0.1785,0.2696)$ and the red ones (labeled by superscript (2)) start from the initial point $\left(p_{1}^{2}(0), p_{2}^{2}(0)\right)=(0.1786,0.2696)$. After a series of iterations, great impacts will emerge in both ICs' prices, even though the initial price of $\mathrm{IC}_{1}$ alters a little.

4.2. Private Leadership. In this case, the numerical simulations show the effect of the parameter $k_{2}$ and the price adjustment speed of $\mathrm{IC}_{2}$, on the stability of system (38).
Figures 5(a) and 5(b) show the bifurcation diagram with respect to $k_{2}$ and the corresponding maximum Lyapunov exponents of system (38), respectively. Figure 6 shows five situations of phase portraits with different $k_{2}$ of system (38). We can see system (38) loses its stability through flip bifurcation, and chaotic attractors occur after the accumulation of a period-doubling cascade. The results demonstrate that the insurance market is stable for relatively small values of $k_{2}$, and a faster adjustment speed is disadvantageous for system (38) to keep the stability. Figure 7 shows the sensitive dependence on the initial conditions of system (38) when $k_{1}=0.7$ and $k_{2}=0.95$. Figures $7(\mathrm{a})$ and $7(\mathrm{~b})$ show the orbits of $\mathrm{IC}_{1}$ 's price and $\mathrm{IC}_{2}$ 's price, respectively, where the blue 


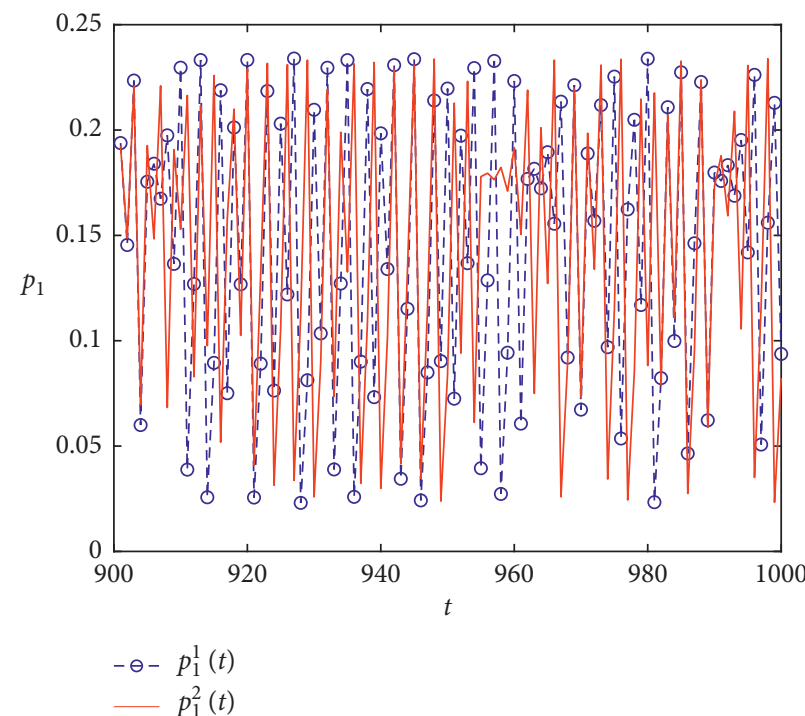

(a)

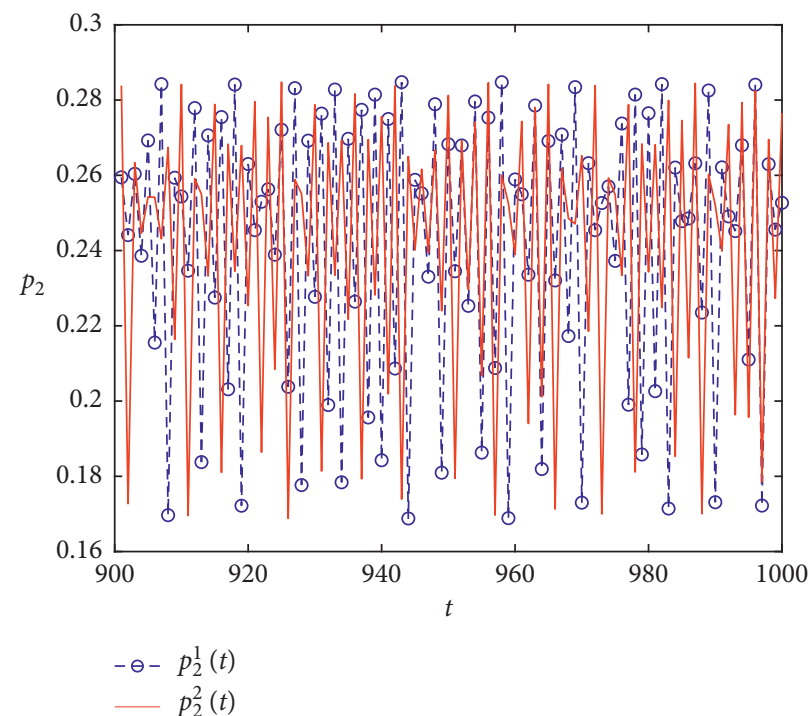

(b)

Figure 4: Sensitive dependence on initial conditions for system (12) in the time periods $[900,1000]$ when $k_{1}=3$ and $k_{2}=0.5$.

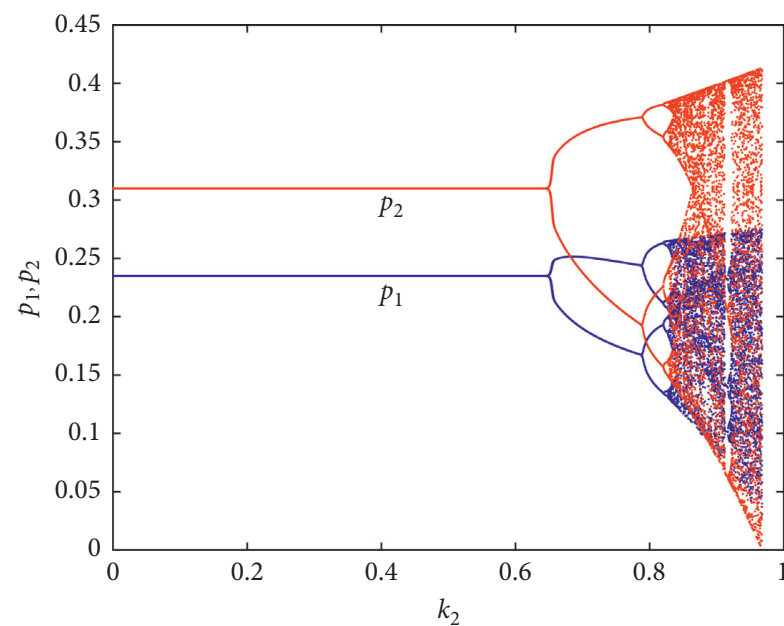

(a)

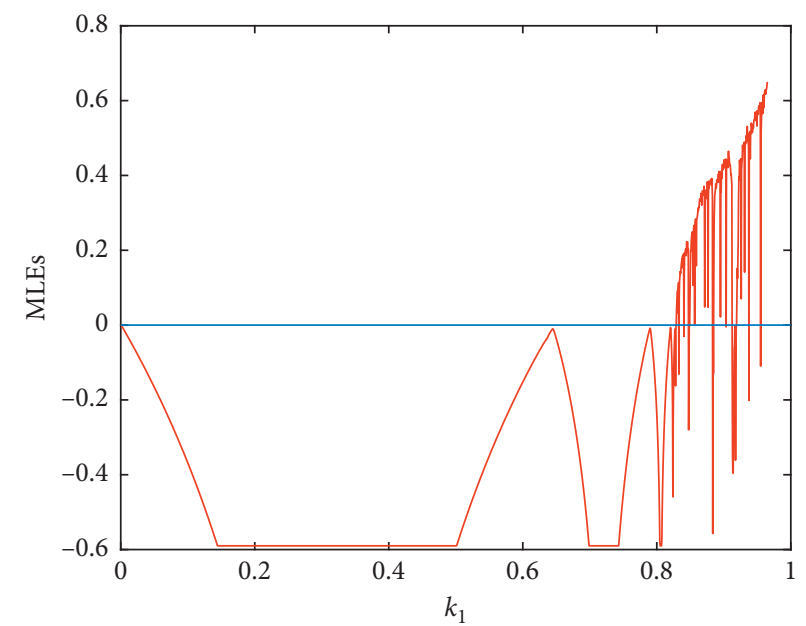

(b)

FIgURE 5: Bifurcation diagram and MLEs for system (38) with respect to parameter $k_{2}$ when $k_{1}=0.7$.

ones (labeled by superscript (1)) start from the initial point $\left(p_{1}^{1}(0), p_{2}^{1}(0)\right)=(0.2351,0.3101)$ and the red ones (labeled by superscript (2)) start from the initial point $\left(p_{1}^{2}(0), p_{2}^{2}(0)\right)=(0.2351,0.3102)$. We can see that the difference between the orbits with slightly deviated initial values builds up rapidly after a series of iterations, although their states are indistinguishable at the beginning.

4.3. The Comparison of Welfare and Profit for Two Games. We now compare the welfare and profit levels for the above two sequential-move games (public leadership and private leadership). Keeping fixed $\alpha=0.7, \quad \beta=0.2, \delta=0.5$, $c_{1}=0.13$, and $c_{2}=0.1$, Figure $8(\mathrm{a})$ shows the values of the welfare of $\mathrm{IC}_{1}$, and Figure 8(b) shows the values of the profit of $\mathrm{IC}_{2}$. The values of the welfare and profit in the Nash equilibrium state of both games are marked, where the red points refer to the welfare and profit at the Nash equilibrium point $E_{4}$ of the game (12), and the blue points refer to the welfare and profit at the Nash equilibrium point $E_{8}$ of the game (38). We can see that the values of the welfare and profit at the two Nash equilibrium points are positive, where $\pi_{1}\left(E_{4}\right)$ is greater than $\pi_{1}\left(E_{8}\right)$ and $\pi_{2}\left(E_{4}\right)$ is less than $\pi_{2}\left(E_{8}\right)$. The results show that an IC, whether public or private, is more profitable in the Nash equilibrium state when it is the leader in the price competition game.

\section{Chaos Control}

As can be seen from the above numerical simulations that price adjustment speeds have a great influence on the stability of systems (12) and (38), the dynamical behaviors of 

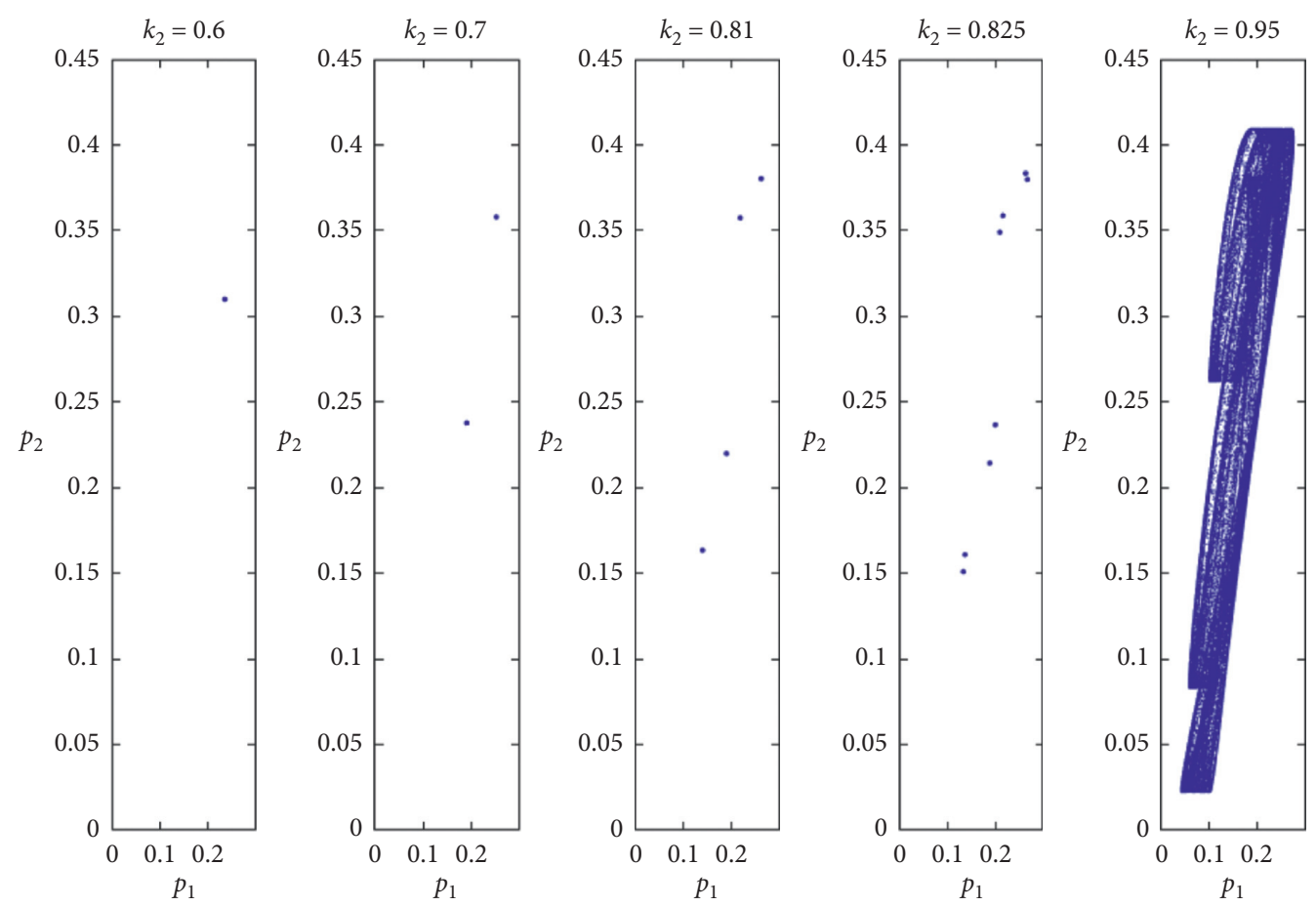

FIgURE 6: Phase portraits for Figure 5 with various values of $k_{2}$.

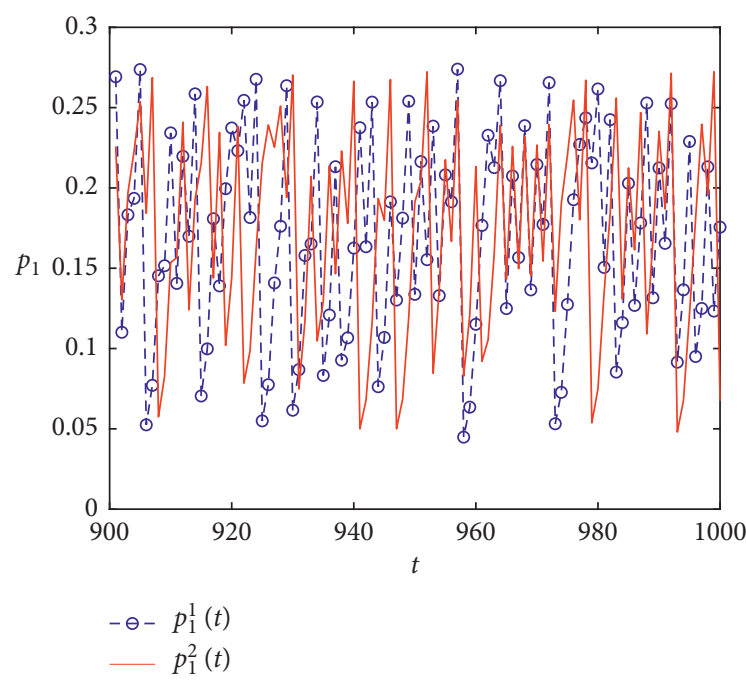

(a)

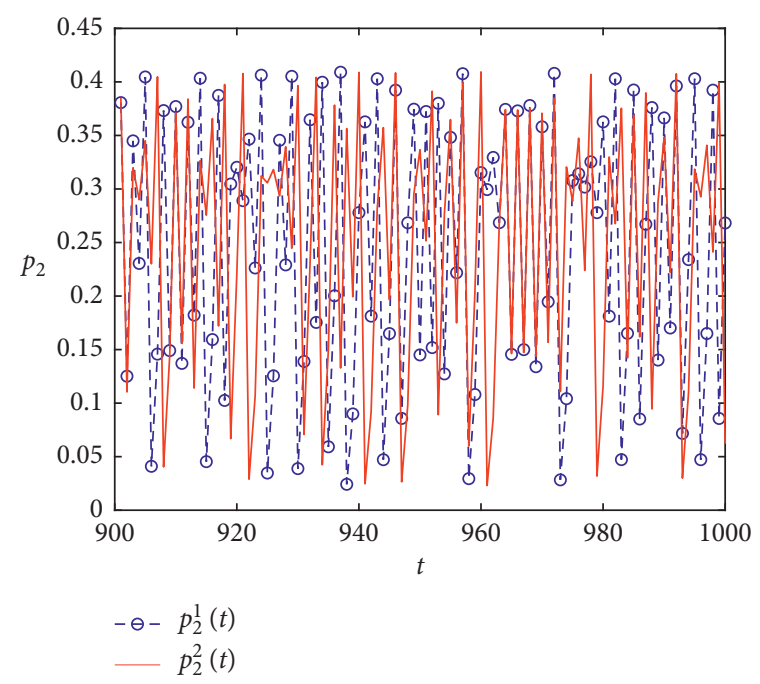

(b)

FIgURE 7: Sensitive dependence on initial conditions for system $(38)$ in the time periods $[900,1000]$ when $k_{1}=0.7$ and $k_{2}=0.95$.

both two systems will be chaotic when the parameters fail to locate in the stable region. In practical application, the appearance of chaos is not expected, we hope that the occurrence of chaos can be avoided or controlled, and the insurance market can be controlled to a balance when it runs irregularly. In this section, we use the time-delayed feedback 


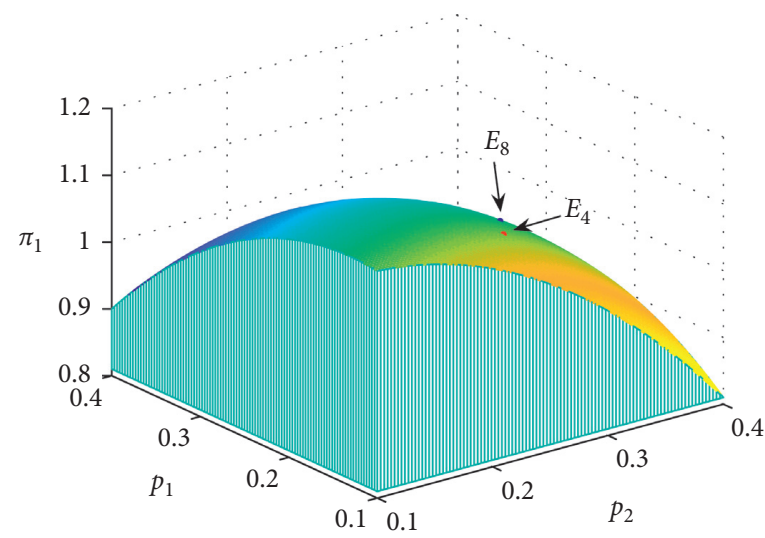

(a)

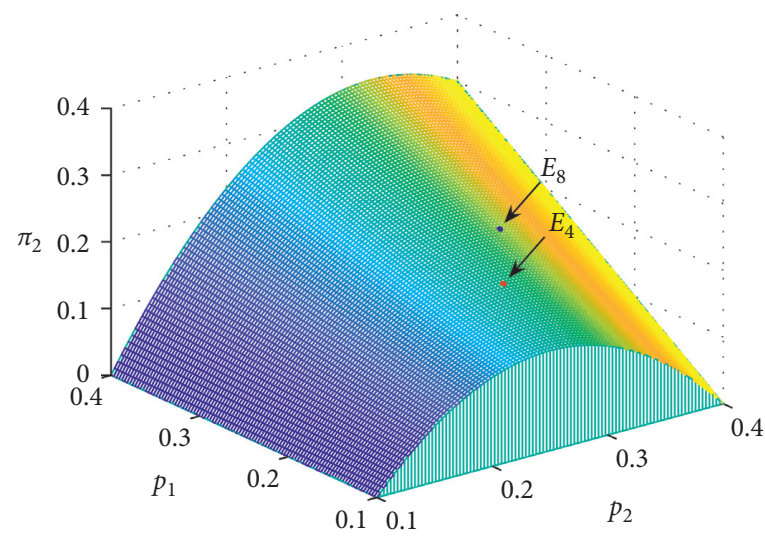

(b)

Figure 8: The welfare of $\mathrm{IC}_{1}$ and the profit of $\mathrm{IC}_{2}$.

control method to control the chaotic phenomenon [37-40]. Similar to the fourth section, we divide the following two cases for numerical simulations.
5.1. Public Leadership. We modify the equations of system (12) by inserting the control action $\phi\left(p_{i}(t)-p_{i}(t+1)\right)$, where $\phi>0$ is the controlling coefficient. Then, the controlled system can be given by

$$
\left\{\begin{aligned}
p_{1}(t+1)= & p_{1}(t)+\frac{k_{1} p_{1}(t)}{4 \beta\left(1-\delta^{2}\right)}\left\{\delta\left[\alpha(1-\delta)-c_{2}\right]+2 c_{1}\left(2-\delta^{2}\right)+\left(3 \delta^{2}-4\right) p_{1}(t)\right\}+\phi\left(p_{1}(t)-p_{1}(t+1)\right) \\
p_{2}(t+1)= & p_{2}(t)+\frac{k_{2} p_{2}(t)}{\beta\left(1-\delta^{2}\right)}\left[\alpha(1-\delta)+c_{2}+\delta p_{1}(t)-2 p_{2}(t)\right] \\
& +\frac{\delta k_{1} k_{2} p_{1}(t) p_{2}(t)}{4 \beta^{2}\left(1-\delta^{2}\right)^{2}}\left\{\delta\left[\alpha(1-\delta)-c_{2}\right]+2 c_{1}\left(2-\delta^{2}\right)+\left(3 \delta^{2}-4\right) p_{1}(t)\right\}+\phi\left(p_{2}(t)-p_{2}(t+1)\right)
\end{aligned}\right.
$$

which can be rewritten as

$$
\left\{\begin{aligned}
p_{1}(t+1)= & p_{1}(t)+\frac{k_{1} p_{1}(t)}{4 \beta\left(1-\delta^{2}\right)(1+\phi)}\left\{\delta\left[\alpha(1-\delta)-c_{2}\right]+2 c_{1}\left(2-\delta^{2}\right)+\left(3 \delta^{2}-4\right) p_{1}(t)\right\}, \\
p_{2}(t+1)= & p_{2}(t)+\frac{k_{2} p_{2}(t)}{\beta\left(1-\delta^{2}\right)(1+\phi)}\left[\alpha(1-\delta)+c_{2}+\delta p_{1}(t)-2 p_{2}(t)\right] \\
& +\frac{\delta k_{1} k_{2} p_{1}(t) p_{2}(t)}{4 \beta^{2}\left(1-\delta^{2}\right)^{2}(1+\phi)}\left\{\delta\left[\alpha(1-\delta)-c_{2}\right]+2 c_{1}\left(2-\delta^{2}\right)+\left(3 \delta^{2}-4\right) p_{1}(t)\right\} .
\end{aligned}\right.
$$

It is easy to see that the controlled system (60) has the same Nash equilibrium point $E_{4}$ as the original system (12). At $E_{4}$, the Jacobian matrix of system (60) takes the form 


$$
J\left(E_{4}\right)=\left(\begin{array}{cc}
1-\frac{k_{1}\left(4-3 \delta^{2}\right) p_{1}^{*}}{4 \beta\left(1-\delta^{2}\right)(1+\phi)} & 0 \\
\frac{k_{2} \delta p_{2}^{*}}{\beta\left(1-\delta^{2}\right)(1+\phi)}-\frac{k_{1} k_{2} \delta\left(4-3 \delta^{2}\right) p_{1}^{*} p_{2}^{*}}{4 \beta^{2}\left(1-\delta^{2}\right)(1+\phi)} & 1-\frac{2 k_{2} p_{2}^{*}}{\beta\left(1-\delta^{2}\right)(1+\phi)}
\end{array}\right) .
$$

Figure 2(a) shows that chaotic behavior of the original system (12) occurs when parameter values are fixed as $\left(\alpha, \beta, \delta, c_{1}, c_{2}, k_{1}, k_{2}\right)=(0.7,0.2,0.5,0.13,0.1,3,0.5)$. By a similar approach in Section 3 to get the stability conditions (i)-(iii) for the original system (12), we can get that all the eigenvalues of the matrix (61) will lie within the unit circle provided that $\phi>0.45$, when the other parameters take above values. In other words, when $\phi>0.45$, the controlled system (60) will be asymptotically locally stable. This result can be numerically shown by Figure 9 .

Figure 9(a) is the bifurcation diagram with respect to $\phi$, where we see that, with the value of $\phi$ increasing, the system is gradually controlled from the chaotic state, 8, 4, 2-period bifurcation to a stable state. Figure 9 (b) shows the stable behaviors of the orbits of the controlled system (60) beginning from the initial state $\left(p_{1}(0), p_{2}(0)\right)=(0.19,0.27)$ for different levels of $\phi$. We can see that the larger the feedback value is, the faster the system tends to be stable.

5.2. Private Leadership. Adding control action $\psi\left(p_{i}(t)-\right.$ $\left.p_{i}(t+1)\right)$ to system (38) and simplifying the system, we get the following form of the controlled system:

$$
\left\{\begin{aligned}
p_{1}(t+1)= & p_{1}(t)+\frac{k_{1} p_{1}(t)}{\beta\left(1-\delta^{2}\right)(1+\psi)}\left(c_{1}-\delta c_{2}-p_{1}(t)+\delta p_{2}(t)\right) \\
& +\frac{\delta k_{1} k_{2} p_{1}(t) p_{2}(t)}{\beta^{2}\left(1-\delta^{2}\right)^{2}(1+\psi)}\left[\alpha(1-\delta)+\delta c_{1}+\left(1-2 \delta^{2}\right) c_{2}-2\left(1-\delta^{2}\right) p_{2}(t)\right] \\
p_{2}(t+1)= & p_{2}(t)+\frac{k_{2} p_{2}(t)}{\beta\left(1-\delta^{2}\right)(1+\psi)}\left[\alpha(1-\delta)+\delta c_{1}+\left(1-2 \delta^{2}\right) c_{2}-2\left(1-\delta^{2}\right) p_{2}(t)\right] .
\end{aligned}\right.
$$

It is obvious that the controlled system (62) has the same Nash equilibrium point $E_{8}$ as the original system (38). At $E_{8}$, the Jacobian matrix of system (62) becomes

$$
J\left(E_{8}\right)=\left(\begin{array}{cc}
1-\frac{k_{1} p_{1}^{* *}}{\beta\left(1-\delta^{2}\right)(1+\psi)} \frac{k_{1} \delta p_{1}^{* *}}{\beta\left(1-\delta^{2}\right)(1+\psi)}-\frac{2 k_{1} k_{2} \delta p_{1}^{* *} p_{2}^{* *}}{\beta^{2}\left(1-\delta^{2}\right)(1+\psi)} \\
0 & 1-\frac{2 k_{2} p_{2}^{* *}}{\beta(1+\psi)}
\end{array}\right) .
$$

As has been shown in Figure 5(a), the chaotic behavior of the original system (38) occurs when parameter values are fixed as $\left(\alpha, \beta, \delta, c_{1}, c_{2}, k_{1}, k_{2}\right)=(0.7,0.2,0.5,0.13,0.1,0.7$, $0.95)$. By computer work on the Jury stability conditions, we can infer that when the other parameters take the above values, the controlled system (62) will be asymptotically locally stable provided that $\psi>0.4725$. As shown in Figure 10(a), with the value of $\psi$ increasing, the system gradually gets out of chaos and achieves stability when $\psi>0.4725$. When $\psi=0.52,0.55$, and 0.58 , the stable behaviors of the orbits of the controlled system (62) beginning from the initial state $\left(p_{1}(0), p_{2}(0)\right)=(0.24,0.32)$ are plotted in Figure 10(b). From Figure 10, we can see that the chaotic system is controlled at the fixed point when the controlling coefficient $\psi$ is properly large.

In a real insurance market, we can consider the control action as the regulation on the price adjustment speed, and we can also consider the control action as the learning ability or adaptability of the market [40]. The time-delayed feedback control method can be used to make the system from a 


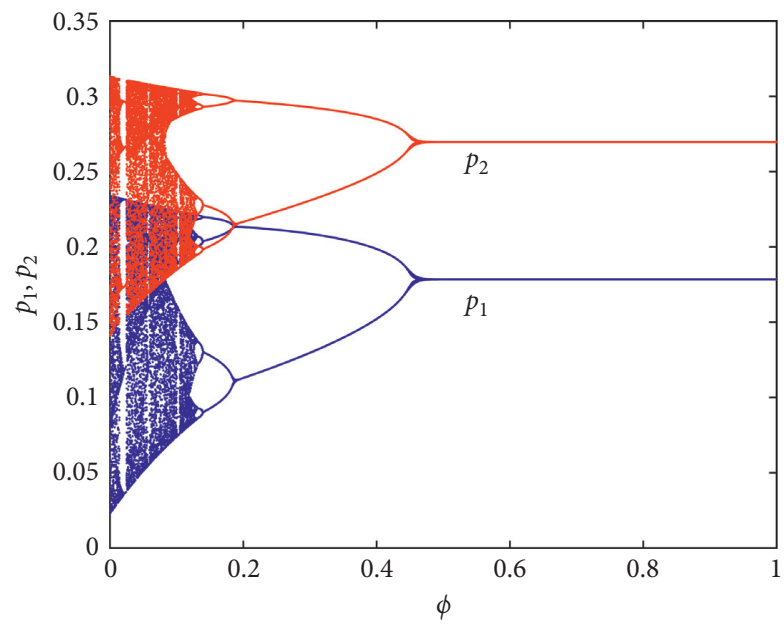

(a)
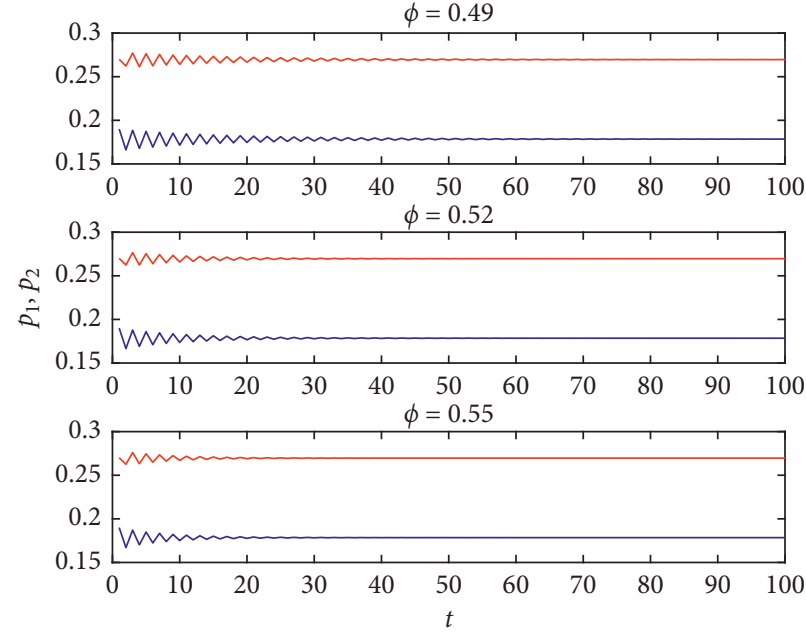

$\begin{aligned}- & p_{1}(t) \\ - & p_{2}(t)\end{aligned}$

(b)

FIgURE 9: (a) Bifurcation diagram for system (60) with respect to the controlling factor $\phi$. (b) Evolutions for system (60) with various values of $\phi$.

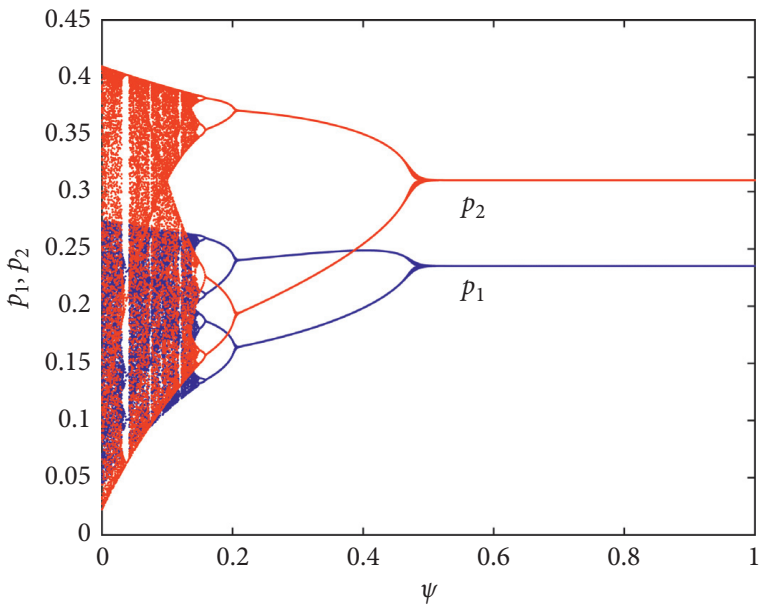

(a)
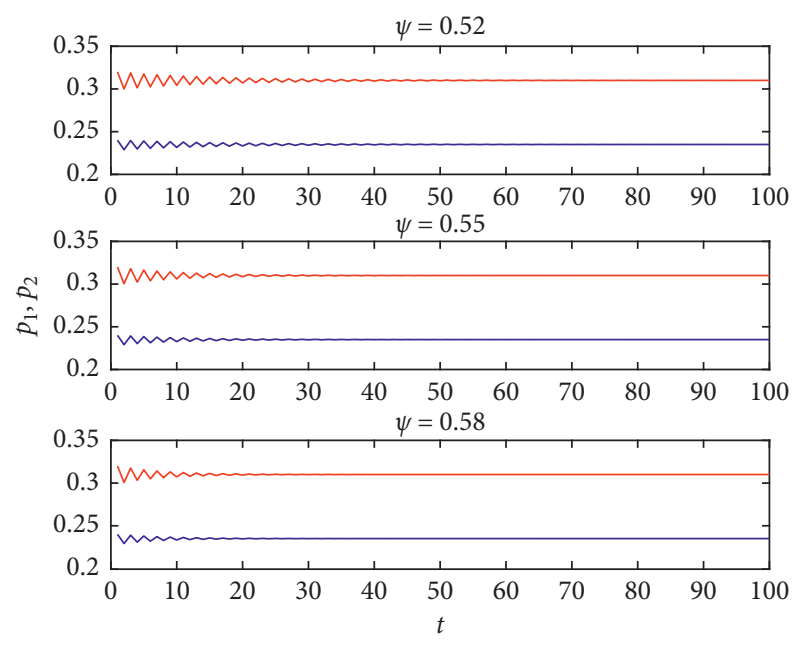

$$
\begin{aligned}
& -p_{1}(t) \\
& -p_{2}(t)
\end{aligned}
$$

(b)

FIGURE 10: (a) Bifurcation diagram for system (62) with respect to the controlling factor $\psi$. (b) Evolutions for system (62) with various values of $\psi$.

chaotic state to stable state, which ensures that the insurance market develops in an orderly way.

\section{Conclusion}

In this paper, we have studied the complex dynamic behaviors of a Stackelberg mixed duopoly game with price competition in an insurance market, wherein a public insurance company competes against a private insurance company. We investigated this problem in two different sequential-move scenarios, public leadership and private leadership games. The equilibrium points including the Nash equilibrium point have been obtained as functions of the system parameters in two cases, and the conditions for the stability of equilibria have been found. We have made some numerical simulations for the system evolution, including stability region, bifurcation diagram, maximal Lyapunov exponents, phase portrait, and sensitive dependence on initial conditions. They show that the price adjustment speeds have a great influence on the system stability, and while varying the values of the price adjustment speeds, complex dynamic behaviors would occur, such as 
period bifurcations and chaos. Meanwhile, we have compared the welfare and profit levels for two sequential-move games. When an insurance company, whether public or private, is the Stackelberg leader in the price competition game, it yields greater welfare (or profit) than as the follower. In addition, we have also shown that the time-delayed feedback control method can be used to force the system back to its stable state from chaos.

\section{Data Availability}

The data used to support the findings of this study are included within the article.

\section{Conflicts of Interest}

The authors declare that they have no conflicts of interest.

\section{Acknowledgments}

This work was supported by the National Social Science Foundation of China (Grant no. 17BJY204) and the Ministry of Education of Humanities and Social Science Project (Grant no. 20YJA910001).

\section{References}

[1] J. L. Zhang and J. H. Ma, "Research on delayed complexity based on nonlinear price game of insurance market," WSEAS Transactions on Mathematics, vol. 10, pp. 368-376, 2011.

[2] W. Xu and J. H. Ma, "Study on the dynamic model of a duopoly game with delay in insurance market," WSEAS Transactions on Mathematics, vol. 11, pp. 599-608, 2012.

[3] E. Ahmed, A. A. Elsadany, and T. Puu, "On bertrand duopoly game with differentiated goods," Applied Mathematics and Computation, vol. 251, pp. 169-179, 2015.

[4] J. Ma and F. Si, "Complex dynamics of a continuous bertrand duopoly game model with two-stage delay," Entropy, vol. 18, no. 7, p. 266, 2016.

[5] L. W. Zhao, "Dynamic analysis and chaos control of bertrand triopoly based on differentiated products and heterogeneous expectations," Discrete Dynamics in Nature and Society, vol. 2020, Article ID 2012680, 17 pages, 2020.

[6] S. S. Askar and A. Al-khedhairi, "Dynamic investigations in a duopoly game with price competition based on relative profit and profit maximization," Journal of Computational and Applied Mathematics, vol. 367, Article ID 112464, 2020.

[7] R. Hu and H. S. Xia, "Chaotic dynamics and chaos control in differentiated bertrand model with heterogeneous players," Grey Systems: Theory and Application, vol. 2, no. 2, pp. 129140, 2012.

[8] H. L. Tu, X. L. Zhan, and X. B. Mao, "Complex dynamics and chaos control on a kind of bertrand duopoly game model considering R \& D activities," Discrete Dynamics in Nature and Society, vol. 2017, Article ID 7384150, 13 pages, 2017.

[9] F. Wang, B. Wang, and R. Xie, "Chaotic dynamics in Bertrand model with technological innovation," Vibroengineering Procedia, vol. 15, pp. 134-140, 2017.

[10] F. Iskhakov, J. Rust, and B. Schjerning, "The dynamics of Bertrand price competition with cost-reducing investments," International Economic Review, vol. 59, no. 4, pp. 1681-1731, 2018.
[11] X. Zhang, D. Sun, S. Ma, and S. Zhang, "The dynamics of a quantum bertrand duopoly with differentiated products and heterogeneous expectations," Physica A: Statistical Mechanics and Its Applications, vol. 557, Article ID 124878, 2020.

[12] B. G. Xin, F. R. Cao, W. Peng, and A. A. Elsadany, "A bertrand duopoly game with long-memory effects," Complexity, vol. 2020, Article ID 2924169, 7 pages, 2020.

[13] L. Shi, Y. Le, and Z. H. Sheng, "Analysis of price stackelberg duopoly game with bounded rationality," Discrete Dynamics in Nature and Society, vol. 2014, Article ID 428568, 8 pages, 2014.

[14] N. H. Shah, G. A. Widyadana, and H. M. Wee, "Stackelberg game for two-level supply chain with price markdown option," International Journal of Computer Mathematics, vol. 91, no. 5, pp. 1054-1060, 2014.

[15] S. N. Wang, "A manufacturer stackelberg game in price competition supply chain under a fuzzy decision environment," IAENG International Journal of Applied Mathematics, vol. 47, pp. 49-55, 2017.

[16] Y. Xiao, Y. Peng, Q. Lu, and X. Wu, "Chaotic dynamics in nonlinear duopoly stackelberg game with heterogeneous players," Physica A: Statistical Mechanics and Its Applications, vol. 492, pp. 1980-1987, 2018.

[17] Y. Peng, Q. Lu, and Y. Xiao, "A dynamic stackelberg duopoly model with different strategies," Chaos, Solitons \& Fractals, vol. 85, pp. 128-134, 2016.

[18] S. J. Sadjadi, H. Asadi, R. Sadeghian, and H. Sahebi, "Retailer stackelberg game in a supply chain with pricing and service decisions and simple price discount contract," PLoS One, vol. 13, no. 4, Article ID e0195109, 2018.

[19] X. Yang, Y. Peng, Y. Xiao, and X. Wu, "Nonlinear dynamics of a duopoly stackelberg game with marginal costs," Chaos, Solitons \& Fractals, vol. 123, pp. 185-191, 2019.

[20] B. Tian, Y. Zhang, and J. Li, "Stochastic perturbations for a duopoly stackelberg model," Physica A: Statistical Mechanics and Its Applications, vol. 545, Article ID 123792, 2020.

[21] K. Hirose and T. Matsumura, "Comparing welfare and profit in quantity and price competition within stackelberg mixed duopolies," Journal of Economics, vol. 126, no. 1, pp. 75-93, 2019.

[22] W. C. Merrill and N. Schneider, "Government firms in oligopoly industries: a short-run analysis," The Quarterly Journal of Economics, vol. 80, no. 3, pp. 400-412, 1966.

[23] J. Ishida and N. Matsushima, "Should civil servants be restricted in wage bargaining? A mixed-duopoly approach," Journal of Public Economics, vol. 93, no. 3-4, pp. 634-646, 2009.

[24] Y. Tomaru and M. Saito, "Mixed duopoly, privatization and subsidization in an endogenous timing framework," The Manchester School, vol. 78, no. 1, pp. 41-59, 2010.

[25] S. Cato and T. Matsumura, "Long-run effects of foreign penetration on privatization policies," Journal of Institutional and Theoretical Economics, vol. 168, no. 3, pp. 444-454, 2012.

[26] L. F. S. Wang and A. Mukherjee, "Undesirable competition," Economics Letters, vol. 114, no. 2, pp. 175-177, 2012.

[27] L. F. S. Wang and J.-Y. Lee, "Foreign penetration and undesirable competition," Economic Modelling, vol. 30, pp. 729-732, 2013.

[28] A. Y. Tao, Y. J. Zhu, and X. Q. Zou, "Welfare comparison of leader-follower models in a mixed duopoly," Journal of Applied Mathematics, vol. 2013, Article ID 320712, 7 pages, 2013.

[29] J. A. Gelves and J. S. Heywood, "Privatizing by merger: the case of an inefficient public leader," International Review of Economics \& Finance, vol. 27, pp. 69-79, 2013. 
[30] A. Dixit, "A model of duopoly suggesting a theory of entry barriers," The Bell Journal of Economics, vol. 10, no. 1, pp. 20-32, 1979.

[31] J. Häckner, "A note on price and quantity competition in differentiated oligopolies," Journal of Economic Theory, vol. 93, no. 2, pp. 233-239, 2000.

[32] G. I. Bischi and A. Naimzada, "Global analysis of a dynamic duopoly game with bounded rationality," Advances in Dynamic Games and Applications, vol. 5, pp. 361-385, 1999.

[33] A. A. Elsadany, "Dynamics of a cournot duopoly game with bounded rationality based on relative profit maximization," Applied Mathematics and Computation, vol. 294, pp. 253-263, 2017.

[34] S. S. Askar, "On complex dynamics of cournot-bertrand game with asymmetric market information," Applied Mathematics and Computation, vol. 393, Article ID 125823, 2021.

[35] J. J. Long and H. Huang, "A dynamic stackelberg-cournot duopoly model with heterogeneous strategies through oneway spillovers," Discrete Dynamics in Nature and Society, vol. 2020, Article ID 3251609, 11 pages, 2020.

[36] Y. Peng, Q. Lu, Y. Xiao, and X. Wu, "Complex dynamics analysis for a remanufacturing duopoly model with nonlinear cost," Physica A: Statistical Mechanics and Its Applications, vol. 514, pp. 658-670, 2019.

[37] Z. Ding, Q. Wang, and S. Jiang, "Analysis on the dynamics of a cournot investment game with bounded rationality," Economic Modelling, vol. 39, pp. 204-212, 2014.

[38] Z. Ding, Q. Li, S. Jiang, and X. Wang, "Dynamics in a cournot investment game with heterogeneous players," Applied Mathematics and Computation, vol. 256, pp. 939-950, 2015.

[39] L. Zhao, J. Du, and Q. Wang, "Nonlinear analysis and chaos control of the complex dynamics of multi-market cournot game with bounded rationality," Mathematics and Computers in Simulation, vol. 162, pp. 45-57, 2019.

[40] H. Garmani, D. A. Omar, M. El Amrani, M. Baslam, and M. Jourhmane, "A dynamic duopoly game with content providers' bounded rationality," International Journal of Bifurcation and Chaos, vol. 30, no. 7, Article ID 2050095, 2020. 